Review

\title{
Recent Advances in Wearable Sensing Technologies
}

\author{
Alfredo J. Perez ${ }^{1, *,+(\mathbb{D})}$ and Sherali Zeadally ${ }^{2, *,+}$ (D) \\ 1 TSYS School of Computer Science, Columbus State University, Columbus, GA 31909, USA \\ 2 College of Communication and Information, University of Kentucky, Lexington, KY 40506, USA \\ * Correspondence: perez_alfredo@columbusstate.edu (A.J.P.); szeadally@uky.edu (S.Z.) \\ + These authors contributed equally to this work.
}

check for updates

Citation: Perez, A.J.; Zeadally, S. Recent Advances in Wearable Sensing Technologies . Sensors 2021, 21, 6828. https://doi.org/10.3390/s21206828

Academic Editor: Paolo Visconti

Received: 19 September 2021

Accepted: 6 October 2021

Published: 14 October 2021

Publisher's Note: MDPI stays neutral with regard to jurisdictional claims in published maps and institutional affiliations.

Copyright: (c) 2021 by the authors. Licensee MDPI, Basel, Switzerland. This article is an open access article distributed under the terms and conditions of the Creative Commons Attribution (CC BY) license (https:// creativecommons.org/licenses/by/ $4.0 /)$.

\begin{abstract}
Wearable sensing technologies are having a worldwide impact on the creation of novel business opportunities and application services that are benefiting the common citizen. By using these technologies, people have transformed the way they live, interact with each other and their surroundings, their daily routines, and how they monitor their health conditions. We review recent advances in the area of wearable sensing technologies, focusing on aspects such as sensor technologies, communication infrastructures, service infrastructures, security, and privacy. We also review the use of consumer wearables during the coronavirus disease 19 (COVID-19) pandemic caused by the severe acute respiratory syndrome coronavirus 2 (SARS-CoV-2), and we discuss open challenges that must be addressed to further improve the efficacy of wearable sensing systems in the future.
\end{abstract}

Keywords: wearables; smartphones; sensing; fitness; mobile payments; financial technology; m-health; crowdsensing; Internet of Things; security; privacy; energy; COVID-19; SARS-CoV-2

\section{Introduction}

Wearable sensing technologies continue to improve rapidly with advances in sensors, communication technologies, and artificial intelligence (AI) in the past decade. Research and development in wearable sensing technologies are fueling a revolution in the creation of novel services in gaming, fitness, entertainment, and specialized applications in industries such as healthcare, security, and defense, among others. In 2020, the market for wearable devices was USD 80 billion, which has tripled in terms of annual revenue since 2014 and it is expected to reach USD138 billion by 2025 [1]. In the consumer wearables market, in 2019, smartwatches and wristbands dominated the market with a combined market share of $51 \%$; as of 2021, the leading wearables are ear-worn wearables with a market share of $48 \%$, followed by a $37 \%$ combined market share of smartwatches and wristbands [2]. Figure 1 presents the consumer wearable devices' market share by device type (2019-2022).

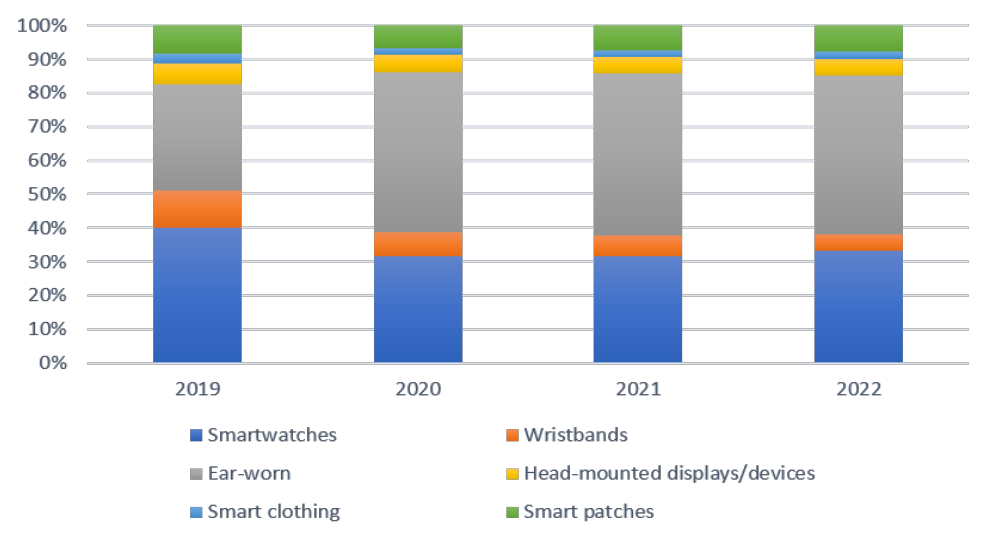

Figure 1. Consumer wearables device market share (2019-2022). 
Ear-worn wearables, in special hearables such as true wireless stereo (TWS) wearables, have surged from almost zero market share to a significant share of the wearable device market [1] since the introduction of Apple AirPods in 2016, and have significantly increased during the coronavirus disease (COVID-19) pandemic [3], caused by severe acute respiratory syndrome coronavirus 2 (SARS-CoV-2), as many people have worked and studied from their homes worldwide. During the pandemic, smart reusable masks that can detect SARSCoV-2 and self-sterilize have become an active area of research and development [4-8]. The COVID-19 pandemic has also positively impacted the adoption of other consumer wearable technologies for mobile payment systems, patient tracking, contact tracing, and remote patient monitoring and treatment [9-12]. Combined fitness/medical-connected services was the leading market for wearable sensing technologies as of 2020 [13-15]. Other markets such as industrial wearables services, entertainment/gaming (i.e., augmented reality (AR) games and devices), and wearables for defense and security are also surging in popularity with recent technological advances in wearable technologies.

According to latest market research analysis, by 2025, the wearable payments services market (around USD 72 billion by 2025) is expected to be larger than the combined fitness/medical wearables services market by approximately USD10 billion [13-15]. The wearable payments market has grown due to the adoption of near-field communication (NFC) in smartphones by manufacturers supporting financial payment standards [16-18], and the incorporation in the near future of NFC in new generations of smartwatches, fitness trackers, and other wearables such as smart rings [19]. However, by 2028, it is forecasted that the wearable fitness market will be approximately USD 138.7 billion [20], while the wearable payment services will remain around USD 80 billion [21]. Figure 2 presents the market value of wearable services for the years 2018-2020, and a projection for 2025 based on available market research data [13-15,22].

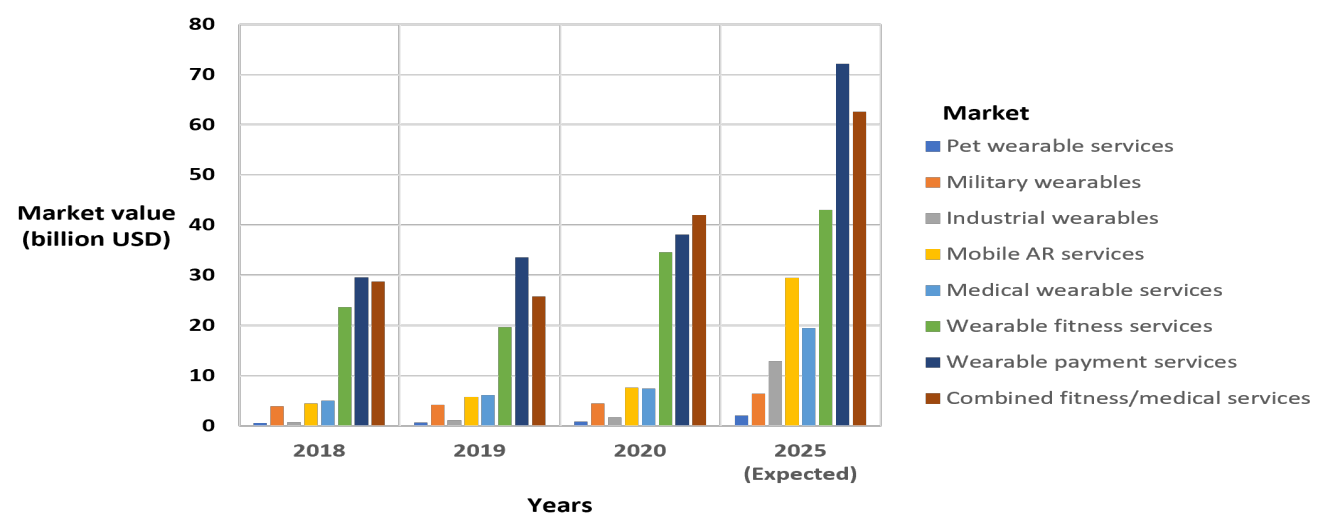

Figure 2. Wearable services market value.

Consumer wearable sensing systems were initially researched with cellphones and smartphones during the second half of the 2000s. During that time, the widespread adoption of cellular communication in the world, the mobile Internet, and the embedding of sensors in cellphones such as location sensors, accelerometers, and cameras paved the way to the development of sensing applications (in particular applications related to humancentric activities) in urban environments at a low cost compared with the deployment of static wireless sensor networks (WSNs) to achieve the same human-centric sensing goals [23]. The research in this area led to the development of many applications in the context of participatory and crowdsensing systems $[24,25]$ using not only embedded cellphone sensors, but using external sensors connected via Bluetooth. Table 1 presents a summary of related works in mobile and wearable sensing during the past decade. 
Table 1. Summary of survey works in mobile and wearable sensing.

\begin{tabular}{cll}
\hline References & Year & Title \\
\hline$[24]$ & 2010 & A survey of mobile phone sensing \\
\hline$[25]$ & 2011 & $\begin{array}{l}\text { A survey on privacy in mobile participatory sensing } \\
\text { applications }\end{array}$ \\
\hline$[26]$ & 2012 & $\begin{array}{l}\text { A survey on human activity recognition using } \\
\text { wearable sensors }\end{array}$
\end{tabular}

2012 Mobile phone sensing systems: A survey

Remarks

Review of applications and architectures for smartphone sensing in human-centric and participatory sensing systems. No mention of wearables

Review of privacy mechanisms for smartphone-based crowdsensing systems. No mention of wearables.

Review of machine learning (ML) models to classify activities using wearables. Review does not include deep learning (DL) systems.

Review of mobile-smartphone-based sensing applications in participatory/crowdsensing settings. Mentions two systems that, as of 2012, used electrocardiogram (ECG) sensors.

\begin{tabular}{lll}
\hline [28] & 2013 & Mobile sensing systems \\
\hline$[29]$ & 2014 & $\begin{array}{l}\text { Wearables: Fundamentals, advancements, and a } \\
\text { roadmap for the future }\end{array}$ \\
\hline$[30]$ & 2015 & $\begin{array}{l}\text { A survey of incentive techniques for mobile crowd } \\
\text { sensing }\end{array}$
\end{tabular}

Review of mobile sensing systems based on smartphones and their communication architectures. Provides short review on security.

Review of wearable technology as of 2014 with a focus on sensors and applications. Does not review security or privacy issues.

Review of monetary and nonmonetary incentives mechanisms for mobile crowdsensing systems based on smartphones. Incentives are important in crowdsensing to recruit participants to collect data.

Reviews energy-aware security mechanisms for

[31] 2015 A survey on energy-aware security mechanisms WSNs, mobile devices (focus on smartphones), and network nodes as of 2015. Review does not mention wearables.

\begin{tabular}{|c|c|c|c|}
\hline [32] & 2016 & $\begin{array}{l}\text { Pervasive eHealth services a security and privacy risk } \\
\text { awareness survey }\end{array}$ & $\begin{array}{l}\text { Presents risk awareness and perception for } \\
\text { eHealth wearables using Amazon Mechanical } \\
\text { Turk. }\end{array}$ \\
\hline [33] & 2016 & $\begin{array}{l}\text { Incentive mechanisms for participatory sensing: } \\
\text { Survey and research challenges }\end{array}$ & $\begin{array}{l}\text { Review of application-specific and } \\
\text { general-purpose incentive mechanisms for } \\
\text { mobile crowdsensing systems based on } \\
\text { smartphones. }\end{array}$ \\
\hline [34] & 2016 & $\begin{array}{l}\text { Deep, convolutional, and recurrent models for human } \\
\text { activity recognition using wearables }\end{array}$ & $\begin{array}{l}\text { Reviews and evaluates of deep learning methods } \\
\text { for human activity recognition. }\end{array}$ \\
\hline [35] & 2017 & A survey of wearable devices and challenges & $\begin{array}{l}\text { Review focuses on consumer wearables available } \\
\text { as of } 2017 \text {. Work also addresses security, power, } \\
\text { task offloading, and machine learning. Work } \\
\text { does not address privacy issues. }\end{array}$ \\
\hline [36] & 2017 & $\begin{array}{l}\text { The use of wearables in healthcare-challenges and } \\
\text { opportunities }\end{array}$ & $\begin{array}{l}\text { Reviews applications of wearables in healthcare } \\
\text { from the application perspective. }\end{array}$ \\
\hline [37] & 2017 & $\begin{array}{l}\text { A survey on smart wearables in the application of } \\
\text { fitness }\end{array}$ & $\begin{array}{l}\text { Review of wearables available as of } 2017 \text { in the } \\
\text { context of fitness. Work does not address } \\
\text { security, privacy, power, or ML in wearable } \\
\text { systems. }\end{array}$ \\
\hline [17] & 2017 & $\begin{array}{l}\text { Mobile payment systems: secure network } \\
\text { architectures and protocols }\end{array}$ & $\begin{array}{l}\text { Describes architectures and protocols to enable } \\
\text { mobile payments. From the device perspective, } \\
\text { it focuses on mobile phones. No mention of } \\
\text { wearables. }\end{array}$ \\
\hline
\end{tabular}


Table 1. Cont.

\begin{tabular}{|c|c|c|c|}
\hline References & Year & Title & Remarks \\
\hline [38] & 2018 & Privacy issues and solutions for consumer wearables & $\begin{array}{l}\text { Review of privacy issues in consumer wearables. } \\
\text { Work does not address power or machine } \\
\text { learning. }\end{array}$ \\
\hline [39] & 2018 & $\begin{array}{l}\text { A critical review of consumer wearables, mobile } \\
\text { applications, and equipment for providing } \\
\text { biofeedback, monitoring stress, and sleep in physically } \\
\text { active populations }\end{array}$ & $\begin{array}{l}\text { Review of the utilization of consumer wearables } \\
\text { for stress and sleep monitoring. No privacy or } \\
\text { security issues mentioned in the paper. }\end{array}$ \\
\hline$[40]$ & 2018 & Wearables and the medical revolution & $\begin{array}{l}\text { Reviews the utilization of wearables for medical } \\
\text { use (m-Health). No privacy or security issues } \\
\text { reviewed in the paper. }\end{array}$ \\
\hline [41] & 2019 & $\begin{array}{l}\text { Demystifying IoT security: An exhaustive survey on } \\
\text { IoT vulnerabilities and a first empirical look on } \\
\text { Internet-scale IoT exploitations }\end{array}$ & $\begin{array}{l}\text { Review of security issues and solutions in } \\
\text { Internet of Things (IoT) systems. Review does } \\
\text { not mention wearables. }\end{array}$ \\
\hline [42] & 2019 & $\begin{array}{l}\text { Buddy's wearable is not your buddy: Privacy } \\
\text { implications of pet wearables }\end{array}$ & $\begin{array}{l}\text { Review of privacy issues and possible privacy } \\
\text { violations or privacy leakages to owners of pets } \\
\text { (pet parents) by having their pets use wearables. }\end{array}$ \\
\hline [43] & 2020 & $\begin{array}{l}\text { Design architectures for energy harvesting in the } \\
\text { Internet of Things }\end{array}$ & $\begin{array}{l}\text { Reviews power and energy harvesting } \\
\text { techniques for Internet of Things (IoT) devices } \\
\text { including wearable devices. }\end{array}$ \\
\hline$[44]$ & 2020 & $\begin{array}{l}\text { A comprehensive overview of smart wearables: The } \\
\text { state of the art literature, recent advances, and future } \\
\text { challenges }\end{array}$ & $\begin{array}{l}\text { Bibliographic review of published works related } \\
\text { to wearable devices. This work reviews } \\
\text { published works from } 2010 \text { to } 2019 \text { (before the } \\
\text { COVID-19 pandemic). }\end{array}$ \\
\hline [45] & 2020 & $\begin{array}{l}\text { Use of wearable sensor technology in gait, balance, } \\
\text { and range of motion analysis }\end{array}$ & $\begin{array}{l}\text { Review of wearables and ML systems with a } \\
\text { focus on gait analysis. }\end{array}$ \\
\hline [46] & 2020 & $\begin{array}{l}\text { Wearables and the Internet of Things (IoT), } \\
\text { applications, opportunities, and challenges: A Survey }\end{array}$ & $\begin{array}{l}\text { Review of sensors and applications of wearables } \\
\text { before the COVID-19 pandemic. This work does } \\
\text { not review security, privacy, or ML. }\end{array}$ \\
\hline [9] & 2020 & A survey of COVID-19 contact tracing apps & $\begin{array}{l}\text { Reviews contact tracing apps developed during } \\
\text { the COVID-19 pandemic. }\end{array}$ \\
\hline [47] & 2021 & Wearables for Industrial Work Safety: A Survey & $\begin{array}{l}\text { Review of wearables in the context of industrial } \\
\text { settings. Work focuses on applications of } \\
\text { wearables for industry. }\end{array}$ \\
\hline [48] & 2021 & $\begin{array}{l}\text { A survey on wearable technology: History, } \\
\text { state-of-the-art and current challenges }\end{array}$ & $\begin{array}{l}\text { Review provides a comprehensive historical } \\
\text { review of wearables devices. Reports on } \\
\text { applications and some aspects of security and } \\
\text { privacy. }\end{array}$ \\
\hline
\end{tabular}

Most of the works cited in Table 1 addressed specific aspects of mobile and wearable sensing systems, with many works focusing on smartphone-based sensing/crowdsensing systems in the past decade. In this work, we present a comprehensive review to provide the reader with not only a summary of past works but also new opportunities in wearables. Moreover, the unexpected COVID-19 pandemic has brought to the spotlight the use of wearable sensing technologies, and has positively shifted the perception and adoption of wearable technologies despite their privacy and security issues. Thus, while recent advancements in wearable sensing technologies have paved the way for the emergence of a plethora of services we are currently using in our lives, there are several areas still in need of further research. In this work, we describe current advances in wearable sensing technologies and services, and their use and opportunities to continue moving the field forward. The main contributions of this paper are as follows: 
- We present a comprehensive review of current advances in wearable sensing technologies;

- We describe recent developments in communication, services, security, and privacy technologies for wearables;

- We discuss some research opportunities and challenges that we need to address in the future for wearable sensing technologies.

We organize the rest of the paper as follows: In Section 2, we review the hardware architecture of wearable sensing devices. Section 3 presents communication technologies for wearable sensing. In Section 4, we discuss remote services for wearable sensing. Section 5 reviews security and privacy challenges and solutions for wearable sensing devices. In Section 6, we present challenges and opportunities in wearable sensing. Finally, Section 7 presents concluding remarks. Figure 3 presents the organization of this work.

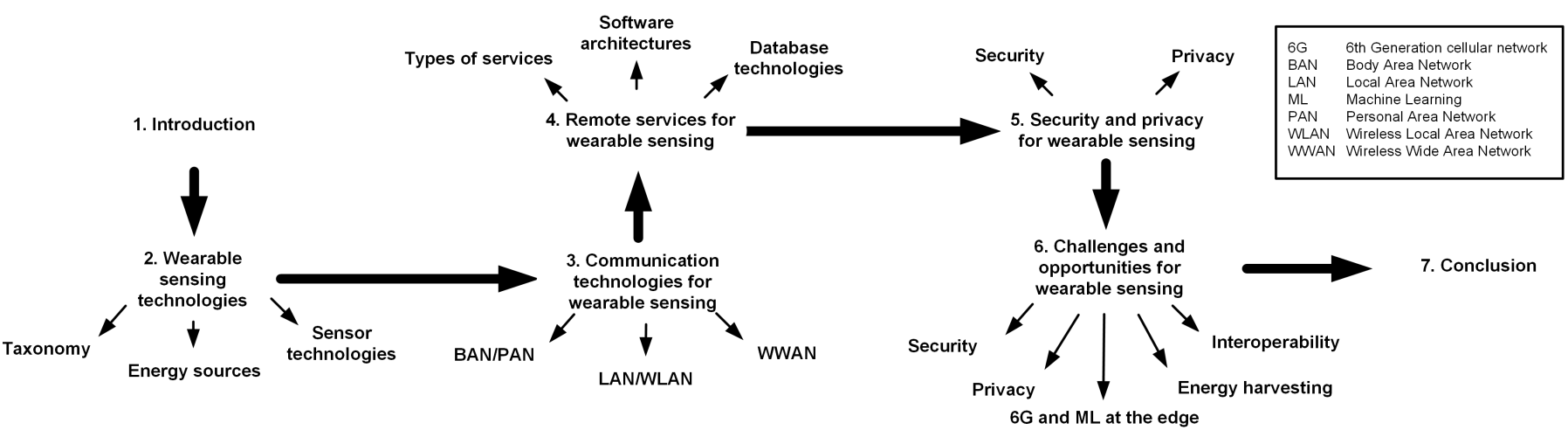

Figure 3. Paper organization.

\section{Wearable Sensing Technologies}

A wearable sensing device is a device that consists of sensors, actuators/output devices, a power generating unit, and an embedded computer, which may be implanted, worn, or carried around by a user $[29,38]$. This user may be a person or, in the case of some wearables, worn by animals. Depending on the characteristics and sensing goals of a wearable sensing device, it may be connected to external systems using the Internet either through a cellular network and/or wireless local area network (WLAN). External systems can store and conduct analysis using artificial intelligence (AI) techniques and may provide feedback to the user of the device. While the ubiquity of wireless sensing technologies has dramatically increased in recent years, early utilization of wearable sensing devices dates back decades ago [29,48]. As of 2021, there are at least 266 companies producing at least 430 wearable sensing devices [49] that can be categorized in a taxonomy based on three layers that include: market type, intrusiveness, and body location.

The first layer (market type) determines the ease with which a general user can typically access a wearable sensor device. Based on the market, devices can be grouped into consumer wearable sensing devices/systems and specialized wearables. Consumer wearable sensing devices can be further categorized into fitness, entertainment/gaming, security, or pet use $[42,50]$. Specialized wearables can only be acquired through specialized vendors, and they comply with special standards or may be regulated by laws that specify who may acquire and/or use them and the specific purposes for which each is designed. Thus, we can categorize specialized wearable sensing devices into industrial, healthcare/medical, security/defense, and research fields.

The second layer (intrusiveness level) determines whether the wearable can be implanted/placed into the body of a living organism (implantable), placed on/worn by a living organism (non-implantable), or carried by a user, for example, on a backpack (external). Under this classification, ingestibles would be classified as an implantable device [51]. The difference between a nonimplantable and an external wearable is whether the device 
is directly in contact with the body of the user (nonimplantable) or not (external). Figure 4 illustrates sensors based on intrusiveness level.

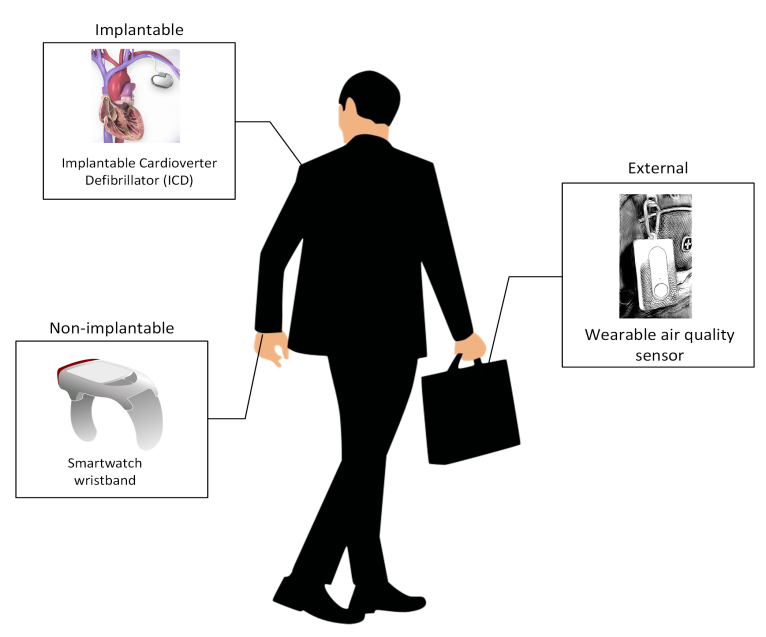

Figure 4. Wearable sensors based on intrusiveness level.

The third layer (body location) determines the placement of the wearable sensing device, which can be the head, trunk, arm, or leg. It is worth noting that these are general positions on the body of a user, so when we refer to the head, this location may include the neck, ears, or eyes. Thus, an example is a consumer, nonimplantable wearable device that can be worn on a wrist (e.g., a fitness wristband).

A wearable sensor device may be composed of the following components depending on its objectives and functionalities (as shown in Figure 5):

- A power unit. This component of the wearable sensor device provides the energy used by the wearable sensor device to operate. Some wearable devices may include rechargeable or nonrechargeable batteries and energy-harvesting technologies [43]. Table 2 presents different types of power-generating units that can be used.

- Sensors. These are electronic and microelectro-mechanical systems (MEMS) components that measure a physical quantity on the user (human-centric) or their surrounding environment (environmental). These sensors may be intrusive to the user (e.g., implanted in the body), with part of the wearable device worn by the user (e.g., smart fabrics [52] and photoplethysmography (PPG) sensors [53]), or carried around/worn by the user (e.g., location trackers [54]). Figure 6 shows a Venn diagram with wearable sensors grouped by type, and Table 3 describes each sensor.

- Processing/control unit. Based on the capabilities and/or design/objectives of the wearable, this component may perform basic calculations, filter data, or execute AI algorithms or control algorithms.

- Embedded storage media. Some wearable sensing devices have a flash-type storage media that stores sensor data for further analysis.

- Network interfaces. Using communication interfaces, a wearable sensor device may create a personal area network (PAN) with other wearable sensors, to communicate with a more powerful device such as a smart phone, or to directly forward data to a remote service.

- Actuators. Actuator components produce vibrations, sound, and visual cues (e.g., lights, screens, or heads-up displays) to notify the user about the device's status. Some wearable sensing devices may not send data to a remote server/service, but they may provide automated feedback or execute an intrusive action on the user (e.g., an automatic defibrillator [55] and wearables for automated medication delivery [56,57] using microneedles) without the need for external systems, and some wearables provide information on a smartphone screen. 
If smartphones are classified as external wearable sensing devices based on intrusiveness, as of 2021, the most-used wearable sensors (from those presented in Table 3) were the sensors embedded in most smartphones. These sensors are the microphone, location sensors, CMOS/CCD camera sensors, accelerometers, gyroscopes, and, to a lesser extent, the NFC interface as a contactless payment sensor. According to the 2021 Ericsson mobility report [58], as there are 5.5 billion smartphones in the world, there are 5.5 billion microphones, 5.5 billion location sensors, 5.5 billion CMOS/CCD cameras, and 5.5 billion accelerometers and gyroscopes collecting data in the world. If considered a wearable, the smartphone would be the most-used wearable during the COVID-19 pandemic caused by SARS-CoV-2. As these sensors are commonly available in most if not all smartphones, the NFC interface with 2.2 billion NFC-enabled smartphones/smartphone-like devices (e.g., tablets) [59] is next.

If the smartphone is not considered a wearable, then the most-available wearable sensors are accelerometers embedded in 708 million smartwatches and activity tracker units shipped between 2018 and 2021 (projection) [60]. However, if it is assumed that all true wireless stereo (TWS) hearables have microphones, then there would be 709 million microphones shipped as part of the TWSs sold between 2018 and 2021 (projection) [61]. After these sensors, the most commonly used sensor is the photoplethysmography(PPG) sensor available in many smartwatches, activity trackers, and pulse oximeters [62].

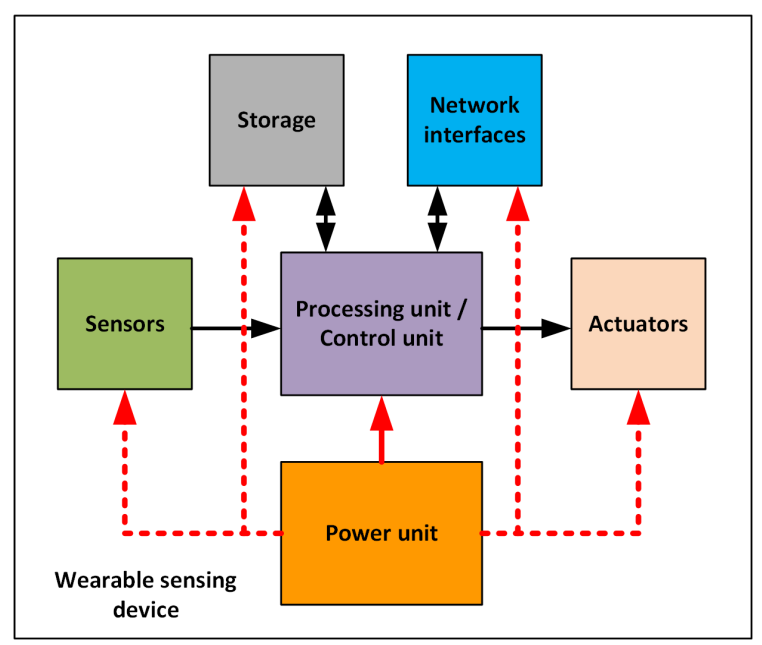

Figure 5. Typical components of a wearable sensing device. The red dotted line indicates possible connection.

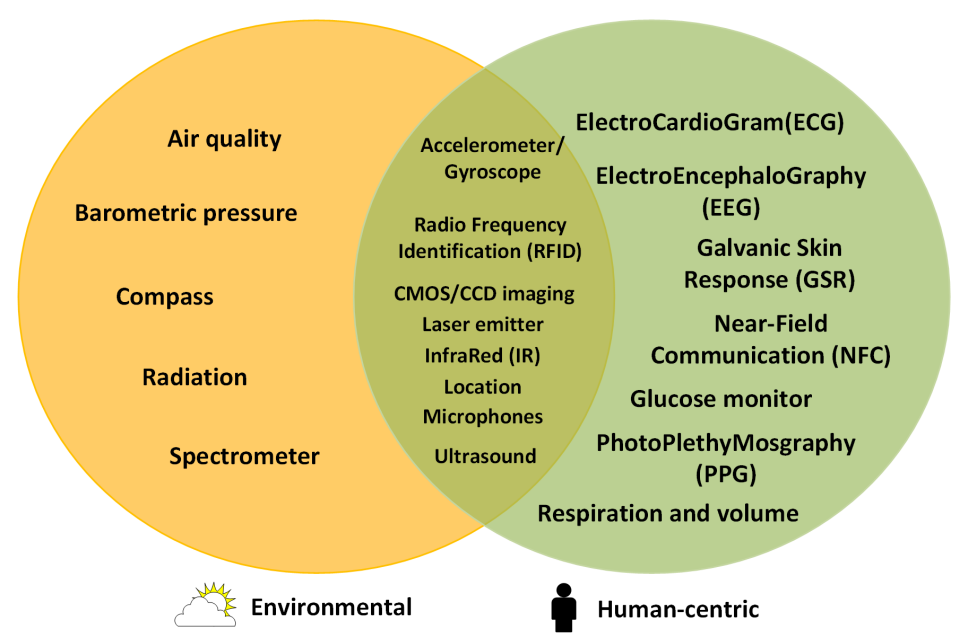

Figure 6. Typical sensors available in wearable devices grouped by type of collected data. 
Table 2. Energy sources for wearable sensing devices.

\begin{tabular}{|c|c|c|}
\hline Energy Source & Description & $\begin{array}{l}\text { Examples of Wearable } \\
\text { Sensing Devices }\end{array}$ \\
\hline Nonrechargeable batteries & $\begin{array}{l}\text { Use of standard-size small or } \\
\text { specialized-size batteries that } \\
\text { power a wearable sensing } \\
\text { device }\end{array}$ & $\begin{array}{l}\text { Insulin pumps, cochlear } \\
\text { implants/devices, } \\
\text { implantable cardioverter } \\
\text { defibrillators }\end{array}$ \\
\hline Rechargeable batteries & $\begin{array}{l}\text { Lithium ion batteries that may } \\
\text { be connected to an external } \\
\text { power source to be recharged }\end{array}$ & $\begin{array}{l}\text { Smart watches, smart phones, } \\
\text { heart trackers, insulin pumps, } \\
\text { digital stethoscopes [63], } \\
\text { portable handheld ultrasound } \\
\text { diagnostic devices [64] }\end{array}$ \\
\hline Solar-powered & $\begin{array}{l}\text { Use of photovoltaic (PV) cells } \\
\text { to recharge a battery that } \\
\text { powers a wearable }\end{array}$ & $\begin{array}{l}\text { Smart bracelets [65], smart } \\
\text { watches, external wearables } \\
\text { such as tracking devices, } \\
\text { smart fabrics }\end{array}$ \\
\hline Radiofrequency (RF) & $\begin{array}{l}\text { Use of antennas that extract } \\
\text { energy from radio signals to } \\
\text { recharge a battery or to power } \\
\text { directly a wearable sensor }\end{array}$ & $\begin{array}{l}\text { Radiofrequency identification } \\
\text { (RFID) implants [66], } \\
\text { bioelectronic } \\
\text { stickers/tattoos [67] }\end{array}$ \\
\hline $\begin{array}{l}\text { Movement and mechanical } \\
\text { waves }\end{array}$ & $\begin{array}{l}\text { Use of piezoelectric devices to } \\
\text { extract energy from human } \\
\text { movements [68] or } \\
\text { mechanical waves such as } \\
\text { wind or ultrasound to } \\
\text { recharge a battery or to power } \\
\text { a device [69] }\end{array}$ & $\begin{array}{l}\text { Implantable medical } \\
\text { devices [69], wrist } \\
\text { wearables [70] }\end{array}$ \\
\hline Thermoelectric generators & $\begin{array}{l}\text { Use of body heat to generate } \\
\text { power to recharge a battery or } \\
\text { to power directly a wearable } \\
\text { sensor [71] }\end{array}$ & $\begin{array}{l}\text { Biometric wearables and } \\
\text { smart t-shirts for } \\
\text { electrocardiogram } \\
\text { monitoring [72] }\end{array}$ \\
\hline
\end{tabular}

Table 3. Sensor technologies for wearable sensing devices.

\begin{tabular}{|c|c|c|c|}
\hline Sensor Type & Description/Application & $\begin{array}{l}\text { Wearable Device } \\
\text { Examples }\end{array}$ & $\begin{array}{l}\text { Type of Collected } \\
\text { Data }\end{array}$ \\
\hline Smart fabrics (e-textiles) & $\begin{array}{l}\text { Fabrics developed from traditional materials } \\
\text { (e.g., cotton, polyester, nylon) combined with } \\
\text { materials possessing electrical conductivity, } \\
\text { or that can be embedded/uses to carry other } \\
\text { sensors/electronic components. Some smart } \\
\text { fabrics can detect the presence of chemical } \\
\text { substances [73] }\end{array}$ & $\begin{array}{l}\text { Zephyr compression shirt, } \\
\text { Nadi X smart yoga pants }\end{array}$ & Human-centric \\
\hline $\begin{array}{l}\text { Electrocardiogram (ECG) } \\
\text { sensor }\end{array}$ & $\begin{array}{l}\text { Measures the electrical impulses of the heart } \\
\text { muscle. Usually placed in contact with the } \\
\text { skin. May be used in conjunction with } \\
\text { implantable cardioverter defibrillators. } \\
\text { Provides heart pulse data }\end{array}$ & $\begin{array}{l}\text { Shimmer3 ECG chest unit, } \\
\text { Apple Watch Series } 6\end{array}$ & Human-centric \\
\hline $\begin{array}{l}\text { Near-field communication } \\
\text { (NFC) }\end{array}$ & $\begin{array}{l}\text { Enables communication at short distances } \\
\text { (less than } 10 \mathrm{~cm} \text { ). Used as a wearable } \\
\text { payment sensor }[74,75] \text {. Can be used to } \\
\text { detect proximity and infer location, and for } \\
\text { multiple-factor authentication methods [76]. }\end{array}$ & $\begin{array}{l}\text { NFC Ring, many } \\
\text { smartphones, } \\
\text { smartwaches }\end{array}$ & Human-centric \\
\hline $\begin{array}{l}\text { Galvanic skin response } \\
\text { (GSR) sensor }\end{array}$ & $\begin{array}{l}\text { Measures skin conductivity. Used in } \\
\text { wearables to recognize stress } \\
\text { levels/emotional state of an individual [77]. }\end{array}$ & Empatica E4 wristband & Human-centric \\
\hline
\end{tabular}


Table 3. Cont.

\begin{tabular}{|c|c|c|c|}
\hline Sensor Type & Description/Application & $\begin{array}{l}\text { Wearable Device } \\
\text { Examples }\end{array}$ & $\begin{array}{l}\text { Type of Collected } \\
\text { Data }\end{array}$ \\
\hline
\end{tabular}

\begin{tabular}{llll}
\hline & $\begin{array}{l}\text { Measures blood volume changes. These } \\
\text { sensors illuminate the skin of a wearer and } \\
\text { measure light absorption to determine }\end{array}$ & Wellvue $\mathrm{O}_{2}$ Ring, pulse & \\
$\begin{array}{ll}\text { Photoplethysmography } \\
\text { (PPG) sensor }\end{array}$ & $\begin{array}{l}\text { human body variables including heart } \\
\text { rate [78,79], blood oxygenation levels [80], } \\
\text { and blood pressure when used in } \\
\text { conjunction with an ECG sensor [81]. }\end{array}$ & & \\
& bands and smart watches & & \\
& &
\end{tabular}
conjunction with an ECG sensor [81].

Electroencephalography (EEG) sensors

Measure electrical activity in the scalp of a user. These devices can be used to diagnose abnormal brain activity when used in healthcare applications [82] or to control devices through brain-computer interfaces (BCIs) [83].

Monitor blood glucose levels for people with

Glucose monitors diabetes. Devices can monitor glucose levels continuously or at a single moment in time [84].

Measures skin or ambient temperature.

Infrared (IR) sensor Temperature can be used to predict ovulation in female mammals.

Accelerometer/gyroscope

Detects sudden accelerationmovement.

Accelerometers can be used to detect and characterize human activities [85].

Detects sound. They can be used to detect

Microphone health conditions, ambient sounds, activity, location contexts (e.g., being in a restaurant, hospital, home) [86].

Tracks the locations/places where a user carrying a device with location may be [87]. Location sensors may be outdoor location or indoor location sensors and include technologies such as a global positioning system (GPS; United States), Galileo

Location sensor (European Space Agency), GLONASS (Russia), BeiDou (China) receivers, or the Navigation with Indian Constellation (India) systems. Indoor location technologies/sensors may include sonar-based, dead reckoning, Bluetooth low energy (BLE) beacons, among others [88].

\section{Complementary Metal-Oxide Semiconductor (CMOS)/CCD imaging sensor}

Takes photographs. When combined with AI, it may be used to detect objects and possibly recognize people's identities without consent [89]. May be used to detect emotions in humans.
Emotiv EpocX

Human-centric

\section{Dexcom G6 CGM Human-centric}

Human-

centric/environmental

Ava fertility tracker

Shimmer3 IMU, Samsung

Galaxy Watch 3, activity Human-centric/

trackers, smartphones

Environmental

Eko CORE family of stethoscopes/stethoscope attachments
Human-

centric/Environmental
Game Golf GPS receiver,

Jiobit, Pet tracker, smartphones, most

Humansmartwatches
Iristick,

Ray-Ban/Facebook Stories

smart glasses, $\mathrm{H} 1$

head-mounted smart Human-

glasses, Microsoft

HoloLens, Axon Body 2

body cameras,

smartphones,
Human-
centric/Environmental
Store information about its wearer. RFID can be active or passive and can be used to track

Radiofrequency identification (RFID) tags assets [90]. RFID can be used for location-based systems and to estimate crowd size in crowd-management systems [91].

\section{M RFID tags, ARDES}

Injection needle with RFID chip for cats and dogs, smartphones
Humancentric/Environmental 
Table 3. Cont.

\begin{tabular}{|c|c|c|c|}
\hline Sensor Type & Description/Application & $\begin{array}{l}\text { Wearable Device } \\
\text { Examples }\end{array}$ & $\begin{array}{l}\text { Type of Collected } \\
\text { Data }\end{array}$ \\
\hline Laser emitter & $\begin{array}{l}\text { Laser emitters are used to measure distances } \\
\text { through light detection and ranging (LiDAR) } \\
\text { and there are plans to be integrate them in } \\
\text { future augmented reality (AR) glasses and } \\
\text { smartphones [92]. A laser emitter can also be } \\
\text { used for both acute and chronic pain } \\
\text { management [93]. }\end{array}$ & $\begin{array}{l}\text { CuraviPlus Laser Therapy } \\
\text { Belt for Lower Back Pain, } \\
\text { future smart AR glasses } \\
\text { and smartphones }\end{array}$ & $\begin{array}{l}\text { Human- } \\
\text { centric/Environmental }\end{array}$ \\
\hline Ultrasound sensor & $\begin{array}{l}\text { Detects objects in the proximity of a } \\
\text { user/device [94]. Used also as an imaging } \\
\text { sensor in handheld healthcare medical } \\
\text { devices [64]. }\end{array}$ & $\begin{array}{l}\text { WeWALK smart cane, } \\
\text { UltraCane, SonoQue, and } \\
\text { Clarius portable handheld } \\
\text { ultrasound devices }\end{array}$ & $\begin{array}{l}\text { Human- } \\
\text { centric/Environmental }\end{array}$ \\
\hline Air quality sensor & $\begin{array}{l}\text { Detects harmful gas concentrations/volatile } \\
\text { components [95]. }\end{array}$ & $\begin{array}{l}\text { Atmotube PRO, TZOA, } \\
\text { Flow } 2 \text { by plume labs }\end{array}$ & Environmental \\
\hline Spectrometer & $\begin{array}{l}\text { Separates and measures the spectral } \\
\text { components reflected by a material. The light } \\
\text { spectrum can be used to determine the } \\
\text { components of the material [96]. }\end{array}$ & $\begin{array}{l}\text { GoyaLab IndiGo modular } \\
\text { visible spectrometer }\end{array}$ & Environmental \\
\hline Radiation sensor & $\begin{array}{l}\text { Tracks ionizing [97] and nonionizing [98] } \\
\text { radiation in the proximity of its wearer. }\end{array}$ & $\begin{array}{l}\text { Instadose } 2 \text { Personal } \\
\text { Radiation (X-ray) badge, } \\
\text { Landauer RaySafe i3 } \\
\text { Real-time Personal, } \\
\text { Radiation Dosimetry, } \\
\text { Landauee Tactical } \\
\text { RadWatch }\end{array}$ & Environmental \\
\hline $\begin{array}{l}\text { Barometric pressure } \\
\text { sensor }\end{array}$ & $\begin{array}{l}\text { Detects barometric (atmospheric) pressure. } \\
\text { Can be used to detect movement, } \\
\text { activity }[99,100] \text {, and altitude. }\end{array}$ & Garmin Fenix 5X & Environmental \\
\hline Compass & $\begin{array}{l}\text { Determines orientation and used for } \\
\text { navigation }\end{array}$ & Most smartwatches & Environmental \\
\hline
\end{tabular}

\section{Communication Technologies for Wearable Sensing}

Advances in communication technologies support the current generation of wearable sensing services. From improvements in intrabody, body area networks (BANs), and personal area networks (PANs) to worldwide deployments of broadband wireless network connectivity, and computing paradigms such as cloud computing and blockchain, communication technologies are supporting many services that use wearable sensing technologies to deliver and provide value-added services to their users.

Figure 7 shows a general architecture for a wearable sensing system. In this architecture, wearable sensor devices collect data and conduct filtering or execute basic data analysis and/or models trained using machine learning (ML) algorithms [23]. Some wearable sensing devices may connect to other sensors (intrabody area networks) or to a smartphone using BANs or PANs. At some point, and based on the design or features of the wearable sensing device, the latter may forward the data collected to a remote service using a cellular network or WLAN either directly connected to the Internet or via a smartphone or communication hub that serves as a gateway device for the wearable device. Depending of the application, specialized networks such as tactical communication networks and satellite communication may be used.

Today, technological advances in communication technologies are found in intrabody networks, BANs, and PANs. These networking technologies are used in wearable sensing to connect wearable sensor devices amongst themselves and to other devices such as a smartphone, a communication hub, or actuator devices over a short distance [101]. 
Wireless technologies used in these networks can be of two types: radiofrequency-based wireless body area network (RF-WBAN), and nonradiofrequency-based wireless body area networks (non-RF-WBAN). In the first group (RF-WBAN), technologies include Bluetooth and Bluetooth low energy [102,103], Zigbee [104], IEEE 802.15.6 WBAN [105], near-field communication (NFC) [106], as well as proprietary protocols such as Sensium [107] and ANT [108]. NFC is most used as a contactless payment sensor [109] over short distances (less than $10 \mathrm{~cm}$ ). The drawbacks of RF protocols for wireless sensing devices and intrabody communications include radio signal degradation due to the composition of body tissues (signal attenuation) [110], broadcast of signals at low power to avoid damaging tissues due to heat dissipation, and power consumption issues related to continuous operation. In the second group (Non-RF-WBAN), the use of molecular communication [111-113], ultrasonic communication [114], and wired networks (e.g., the USB personal healthcare device) $[115,116]$ have been proposed as alternatives to wireless communications for PANs and BANs.

Wireless sensing devices use wireless local area networks (WLANs) to connect to the Internet, to other sensing devices, or to local hubs that serve as gateways to other systems and networks using the Transmission Control Protocol/Internet Protocol (TCP/IP) network stack or dedicated protocols such as Continua [115] and ISO/IEEE 11073 [116]. While most wearables connect to WLANs, local hubs, or PANs (i.e., smartphones) to send data to remote services, newer wearables, especially in the consumer market, access remote services using mobile broadband [117].

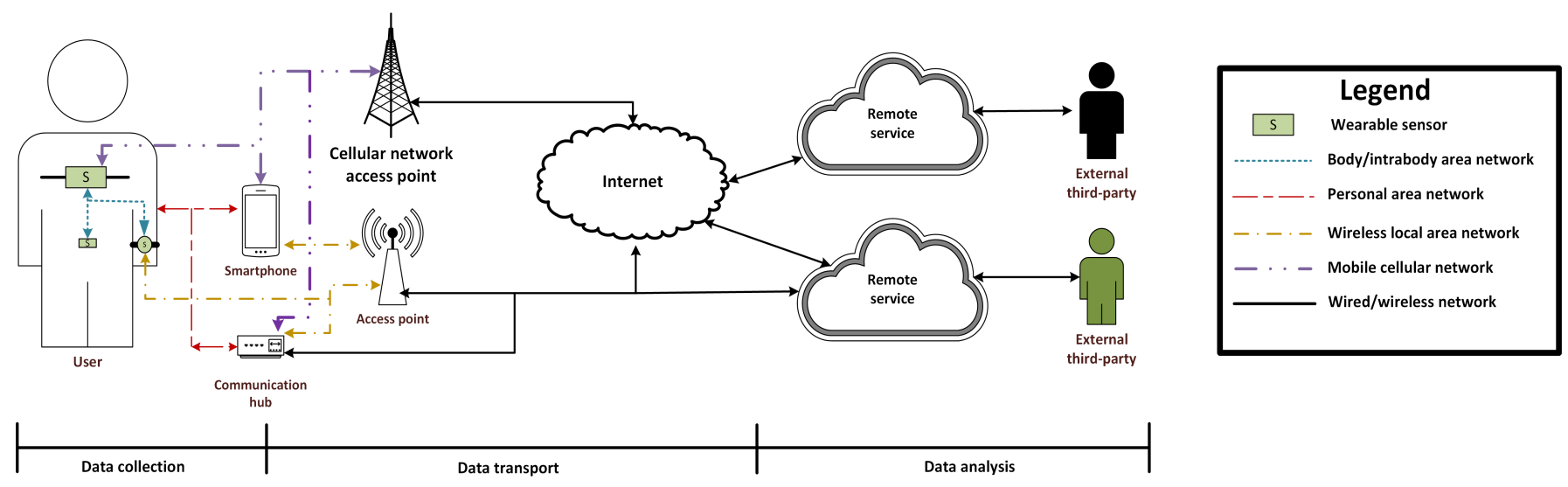

Figure 7. General architecture of wearable sensing systems.

Advances in mobile Internet broadband and cellular networks (4G/5G) along with decreasing costs have fueled the mass adoption and utilization of wearable sensing technologies and services. As of 2021 [58], there were more than 8 billion cellular subscriptions in the world. More than $80 \%$ of these subscriptions are mobile broadband connections and 5.5 billion are smartphone connections. According to Ericsson [58], part of the future improvements in network capacity provided by 5G cellular networks by 2024 will satisfy the growing demand for services including services making use of consumer wearable sensing devices. Other networking solutions exist for wearable sensing technologies in specific markets. These include Mobile Adhoc NETworks (MANETs), intranets, and satellite networks with proprietary protocols [118].

\section{Remote Service Technologies for Wearable Sensing}

In the previous section, we described computer network technologies enabling communication infrastructures for wearable sensing. While these technologies are responsible for transporting data between two entities (i.e., wearable sensors and a service provider), they do not implement a service on their own. The kind of data collected and why the data are being collected, used, and shared create value for stakeholders through the implementation of services. These services may fall into four major system categories [23]: 
location-based services (LBSs), human-centric sensing (HCS), participatory/crowdsensing systems (PS/CSs), and hybrids or combinations of these categories. Table 4 describes examples of these systems.

Wearable sensing services can be implemented using private servers [23], servers deployed in the cloud [119], and more recently as distributed apps (DApps) using blockchain and smart contract technology [120-122]. Remote service implementations making use of hybrid architectures between servers/the cloud and blockchain technology have recently been proposed for participatory/crowdsensing and human-centric systems [123-126]. A drawback of using public blockchains to store sensor data is the high monetary cost when data are uploaded to a public blockchain [127].

For services implemented using private servers and cloud services, remote services use technologies such as Structured Query Language (SQL) relational databases (e.g., Postgres, MySQL, MS SQL Server, and Oracle) and nonrelational (NoSQL) databases (e.g., Apache Ignite, Memcached, Cassandra, Hadoop/Hbase/HDFS, Azure Cosmos, Amazon S3, and Google Cloud Storage). Nonrelational databases are chosen by many of these services because they are useful for storing large amounts of data (big data) in real time. For example, data collected by Uber can be in the order of petabytes (PB) per day [128].

Table 4. Types of wearable sensing systems.

\begin{tabular}{|c|c|c|}
\hline Type of System & Description & $\begin{array}{l}\text { Examples of } \\
\text { Systems }\end{array}$ \\
\hline Location-based systems & $\begin{array}{l}\text { Use location data to track, query, or provide a } \\
\text { service based on location only [129]. }\end{array}$ & $\begin{array}{l}\text { Smart Caddie, OneBusAway [130], Jiobit } \\
\text { pet tracking system, Uber, Lyft }\end{array}$ \\
\hline Human-centric systems & $\begin{array}{l}\text { Use sensors to monitor human-related } \\
\text { physiological variables, activities and behaviors. } \\
\text { Personal monitoring systems (e.g., fitness systems) } \\
\text { and intelligent medical/healthcare systems fall } \\
\text { into this category [131,132] }\end{array}$ & $\begin{array}{l}\text { Fitbit Premium + Health, Garmin } \\
\text { Connect, Samsung Health, Apple } \\
\text { Healthkit }\end{array}$ \\
\hline $\begin{array}{l}\text { Participatory/ crowdsensing } \\
\text { systems }\end{array}$ & $\begin{array}{l}\text { Use collaborative data collected from a crowd to } \\
\text { estimate communal parameters of } \\
\text { interest }[133,134] \text { such as traffic, pollution, noise } \\
\text { levels and others [135]. } \\
\text { Participatory/crowdsensing systems include } \\
\text { systems for crowd management }[91,136,137] \text {, } \\
\text { emergency management [138], and recently } \\
\text { COVID-19 epidemiological systems based on } \\
\text { mobile phones and sensors }[10,11] \text {. }\end{array}$ & $\begin{array}{l}\text { Crowdsync, COVIDNearby, } \\
\text { CovidSens [139], MetroSense [140] }\end{array}$ \\
\hline Hybrid systems & $\begin{array}{l}\text { Systems making use of the characteristics of more } \\
\text { than one class/kind of system above. }\end{array}$ & PokemonGo \\
\hline
\end{tabular}

Many of these systems are implemented in clouds using software engineering architectures based on microservices [141]. Microservices implement a remote service using a collection of small, independent services potentially deployed on different platforms or technology stacks [141]. Some of their advantages over monolithic architectures for software [142] include adaptability to changes in technology, reduced time-to-market (new features for a given remote service may be released as a microservice on its own), scalability, and flexible software engineering development practices (e.g., DevOps [143]) which suit many startup companies designing wearable systems and services. Data collected by remote systems can be analyzed using AI and ML techniques [26,45] such as deep learning (DL) [34], and feedback may be provided to users or to external third parties based on privacy policies or terms of use and commercial agreements [144]. 


\section{Security and Privacy for Wearable Sensing}

Security and privacy are two of the most significant aspects in the adoption of wearable sensing technology and systems in many application areas. For example, in mobile health (m-Health), if a wearable system that delivers medications or provides intrusive actions in the body of its user (e.g., implantable cardioverter defibrilators (ICD) with remote connectivity) has exploitable security flaws, the consequences could be catastrophic. From the privacy perspective, past research on smartphone-based sensing systems [25] demonstrated that certain kinds of data collected (e.g., location data) could be exploited to reveal aspects considered private for a user or a participant in a crowdsensing system. In this section, we first review security issues in wearable systems, and then review privacy aspects in wearables.

\subsection{Security}

Wearable sensing systems are susceptible to similar vulnerabilities and attacks found in other Internet of Thing (IoT) devices and systems. Security attacks, for wearable sensing technologies, can occur in a wearable sensing device, during data transport, or in the remote services collecting and analyzing data by exploiting vulnerabilities not considered at the design phase of a system. Table 5 summarizes vulnerabilities in wearable sensing devices.

In contrast to other IoT devices or computer systems that may be physically isolated or protected, the lack of physical security in wearable devices can be easily exploited by adversaries launching spoofing attacks to submit incorrect/fake data to a remote service $[145,146]$. A second type of spoofing attack (called mule attack [147]) may attempt to tamper with a wearable's context or environment to make the wearable submit incorrect data $[148,149]$. For example, a mule attack on a fitness band or smartwatch to detect or register activity levels could be easily manipulated by an adversary by waving their arm or tying the wearable to a rope and make the fitness band or smartwatch rotate while standing at the same location [147]. Solutions proposed in the literature for spoofing attacks include the utilization of AI to recognize correct patterns/context [150] and the utilization of multiple sensors worn by a user to test the data collection context or to verify the data during collection phase [79,151-153].

When wearables are used in remote services collecting data from users to estimate environmental variables of interest (e.g., pollution, noise, or road traffic levels) through participatory or crowdsensing systems, spoofing attacks can be mitigated at the remote service by taking advantage of the redundant data collected by multiple users to estimate and filter out incorrect, erroneous, or fake data. Methods to filter out data in remote services include kriging, principal component analysis (PCA), Markov random fields (MRFs), Gaussian mixture models (GMMs), stochastic processes [154-158], and anomaly detection algorithms based on ML methods such as support vector machines (SVMs), neural networks (NNs) [159], and recent methods based on DL (i.e., convolutional neural networks (CNNs), and long short-term memory (LSTM) neural networks [160-162]).

A second vulnerability that can be exploited in wearable devices is the limited energy management and harvesting, which an adversary could exploit to perform battery exhaustion attacks and render a wearable ineffective in executing its tasks. In contrast to other IoT devices and computer systems, such as desktops, in which energy/power is not an issue because they are always connected to a reliable power source (i.e., a city's power grid), most wearables use nonrechargeable or rechargeable batteries and/or energyharvesting techniques (as we described in Section 1). Techniques available to mitigate this kind of attack include the development of power-aware frameworks and operating systems that continuously monitor the power consumption of the device $[163,164]$, assessing the software's power consumption before being implemented into a battery-powered device [165-167], and runtime anomaly detection methods that detect abnormal power patterns [168-170]. While most of these methods have been developed for smartphones, 
they can be adapted for wearables and used to detect and mitigate battery exhaustion attacks.

Table 5. Vulnerabilities in wearable sensing devices (adapted from [41]).

\begin{tabular}{|c|c|c|}
\hline Vulnerability & Description & Examples of Attacks \\
\hline Limited physical security & $\begin{array}{l}\text { Unauthorized physical access to a wearable } \\
\text { device by an adversary without difficulty }\end{array}$ & $\begin{array}{l}\text { Physically damaging a device, spoofing } \\
\text { attacks }[145,146], \text { manipulation of a device's } \\
\text { context/environment to make the device } \\
\text { malfunction or incorrectly collect/register } \\
\text { data }[148,149]\end{array}$ \\
\hline Limited power & $\begin{array}{l}\text { Wearable devices use batteries or energy } \\
\text { harvesting techniques; attacks may drain } \\
\text { their batteries and render them unusable }\end{array}$ & Battery exhaustion attacks [171] \\
\hline Weak encryption & $\begin{array}{l}\text { Use of encryption protocols that may not } \\
\text { sufficiently protect data sent by a wearable } \\
\text { due to energy limitations, processing power } \\
\text { limitations, and bad software engineering } \\
\text { practices }\end{array}$ & $\begin{array}{l}\text { Eavesdropping, injection, and denial of } \\
\text { service (DoS) attacks in health monitoring } \\
\text { devices [172] }\end{array}$ \\
\hline Weak authentication & $\begin{array}{l}\text { Failure to authenticate a user, a wearable } \\
\text { device, or data generated by a wearable due } \\
\text { to energy, computational power, poor design, } \\
\text { mode of use, or user interface constraints that } \\
\text { may not allow the implementation of strong } \\
\text { authentication protocols on a wearable } \\
\text { device }\end{array}$ & $\begin{array}{l}\text { Stealing, losing, or duplicating a physical } \\
\text { token for a wearable device [173] }\end{array}$ \\
\hline Unnecessary open ports & $\begin{array}{l}\text { Devices may keep operating system (OS) } \\
\text { ports/network addresses that may be } \\
\text { exploited in security attacks or privacy } \\
\text { violations }\end{array}$ & $\begin{array}{l}\text { Tracking of users using botnets and } \\
\text { Bluetooth low energy (BLE) [174] }\end{array}$ \\
\hline Software vulnerabilities & $\begin{array}{l}\text { Software may be implemented with errors or } \\
\text { weak programming practices that make } \\
\text { wearables vulnerable to security attacks; } \\
\text { some of these weak practices include } \\
\text { backdoors and errors during firmware } \\
\text { updates }\end{array}$ & $\begin{array}{l}\text { Attacks on fitness trackers during firmware } \\
\text { updates [151] } \\
\text { Logic bombs [175] }\end{array}$ \\
\hline
\end{tabular}

The use of encryption protocols that can be broken by an adversary with enough computational resources occurs when manufacturers use weak encryption in their devices (either in software and/or hardware). Weak encryption may enable attackers to eavesdrop on data in transit either to another wearable or to a remote service on the Internet. Weak encryption may occur due to limitations in the software, hardware, power availability, or weak programming practices, which may expose a wearable to attacks. In the past, research has shown that manufacturers sell consumer wearables with a lack of encryption, so can be attacked either through passively eavesdropping Bluetooth connections, through man in the middle (MITM) attacks, or by failing to encrypt data stored locally [172,176-179]. These attacks can violate user privacy, impersonate a user, or fabricate data submitted to a remote service. To mitigate this vulnerability, manufacturers should use hardware that supports strong encryption (e.g., ARM and Intel processors have hardware-specific extensions implementing Advance Encryption Standard (AES) algorithms), strong endto-end encryption protocols (when supported by hardware/software), and good software engineering practices. 
Weak authentication vulnerabilities arise when a wearable device, a wearable's user, or data sent by a wearable cannot be authenticated due to due to energy, computational power, poor design, mode of use, or user interface constraints in the device or the system. Cryptographic authentication mechanisms available for other types of computers may not be enough to authenticate users, data, or wearable devices. For example, usually, login identifiers and passwords are used to authenticate a user in a laptop or desktop environment. However, because many wearable devices can be easily removed by users and worn by somebody else, the use of single-time authentication methods such as passwords are not enough to guarantee who is using a wearable device. To enforce authentication, various user authentication methods have been proposed based on biometrics [180], multifactor authentication mechanisms [76,181], and multiple wearable devices [182,183].

Unnecessary open ports make wearables susceptible to security and privacy attacks. While these attacks, so far, are less common than in other IoTs and computer systems, they are still present in wearables. For example, Issoufaly and Tournoux [174] highlighted how fingerprinting of wearables' BLE medium access control (MAC) addresses can be easily exploited to track users via these addresses. In their research, they found that even though security and privacy features exist in BLE specifications, these features are rarely used. Robles-Cordero et al. [184] arrived at similar conclusions. Becker et al. [185] showed that even with BLE address randomization, passive tracking is possible. Knackmuß et al. [186] also explored unnecessary open port attacks, in which they used a packet sniffer tool to find an open port on a popular infusion pump. While open port vulnerabilities can be easily solved by having good product development practices, they pose a significant threat to wearables.

Other vulnerabilities of wearable devices that can be exploited are those arising from weak software development practices [187]. Software vulnerabilities can lead to malfunctioning, leaks in privacy, manipulation of data, or causing a wearable to execute attacks on other devices over a network (or the Internet). Software vulnerabilities may be caused by weak programming practices that can be present as part of the original software (firmware) with which a wearable is manufactured, or as part of firmware updates. Some of the vulnerabilities, such as inadequate encryption, inadequate authentication, and the unnecessary open ports previously discussed in this section, may be the result of weak programming practices. Weak programming practices can generate significant technical debt $[188,189]$ in wearable sensing systems. Examples in the literature of possible attacks include remotely accessing implantable cardiac devices to make them fail [190] or to violate users' privacy [191]. After Corbin [192] reported that former U.S. Vice President Dick Cheney's pacemaker had software vulnerabilities that could enable hackers to cause heart attacks remotely, the former Vice President disabled the remote access capabilities of his pacemaker.

\subsection{Privacy}

Wearable sensing services may expose users to various privacy threats because the data collected by these services can be potentially linked back to users [193]. Research on user privacy perceptions on the utilization of consumer wearables has identified privacy concerns related to social implications, criminal abuse, facial recognition, access control, social media sync, right to forget, surveillance and sousveillance, speech disclosure, and surreptitious audio/video (A/V) recordings when using a device, which may continuously register users' actions [194]. Table 6 summarizes these privacy concerns. 
Table 6. Wearable user's privacy concerns, as researched by the authors of [194].

\begin{tabular}{ll}
\hline Privacy Concern & Description \\
\hline Social implications & $\begin{array}{l}\text { Unawareness by a network of friends regarding data being } \\
\text { collected about them }\end{array}$ \\
\hline Criminal abuse & Fear that wearable data will be used by criminals to harass a user \\
\hline Facial recognition & $\begin{array}{l}\text { Association and recognition of a bystander to a place or a } \\
\text { situation where the bystander would not wish to be recognized } \\
\text { by others }\end{array}$ \\
\hline Access control & $\begin{array}{l}\text { Fear of users of third-party service providers sharing data } \\
\text { without consent }\end{array}$ \\
\hline Social media sync & $\begin{array}{l}\text { Immediate publishing or sharing by the wearable device without } \\
\text { the knowledge of the user }\end{array}$ \\
\hline Discrete display and visual \\
occlusion & $\begin{array}{l}\text { Notifications/information of users that might be seen by } \\
\text { bystanders who should not have access }\end{array}$ \\
\hline Right to forget & $\begin{array}{l}\text { The user's wish to delete collected data that he or she wants to } \\
\text { forget }\end{array}$ \\
\hline $\begin{array}{l}\text { User fears: surveillance and } \\
\text { sousveillance }\end{array}$ & $\begin{array}{l}\text { Continuous tracking of user activities that might make the user } \\
\text { feel that no matter what they do, everything is recorded }\end{array}$ \\
\hline Speech disclosure & $\begin{array}{l}\text { Capturing speech that a user or bystanders would not want to } \\
\text { record or share }\end{array}$ \\
\hline Surreptitious A/V recording & $\begin{array}{l}\text { Recording of video without permission that might affect } \\
\text { bystanders }\end{array}$ \\
\hline
\end{tabular}

These concerns can be classified into three main privacy issues categories, which include context privacy, bystanders' privacy, and external data sharing privacy [38]. Table 7 presents each privacy concern with a privacy issue and the related solutions found in the literature.

The first privacy issue we present is context privacy. Context privacy comprises the context/actions deemed private by a wearable user that can be inferred based on the data or metadata collected through a wearable. Many wearables are used continuously, and users may not remember that the utilization of a wearable may possibly register all users' actions (and data about users' surroundings), and private information could be inferred [195]. Solutions to solve this issue include methods that only collect data when the user desires it [196-198], and methods to avoid or deny data collection when the user wishes [199]. For both types of solutions, the idea is for the user to create rules at different levels that may be based on raw sensor data readings, or more complex rules that may involve activity recognition at the wearable device. 
Table 7. Privacy concerns and issues for wearables (adapted from [38]).

\begin{tabular}{|c|c|c|}
\hline User Privacy Concern & Privacy Issue & Recently Proposed Solutions \\
\hline $\begin{array}{l}\text { Access control } \\
\text { Location disclosure } \\
\text { Social implications } \\
\text { Discrete display and visual } \\
\text { occlusion } \\
\text { User's fear } \\
\text { Speech disclosure } \\
\text { Right to forget }\end{array}$ & $\begin{array}{l}\text { Context } \\
\text { privacy }\end{array}$ & $\begin{array}{l}\text { Virtual trip lines [196] } \\
\text { Bubble sensing [197] } \\
\text { Privacy bubbles [198] } \\
\text { Virtual walls [199] }\end{array}$ \\
\hline $\begin{array}{l}\text { Speech disclosure } \\
\text { Social implications } \\
\text { Facial recognition } \\
\text { (identification) } \\
\text { Surreptitious A/V recording } \\
\text { User's fears } \\
\text { Location disclosure }\end{array}$ & $\begin{array}{l}\text { Bystanders' } \\
\text { privacy }\end{array}$ & $\begin{array}{l}\text { BlindSpot [200] } \\
\text { Using IR to disable devices [201] } \\
\text { Using Bluetooth to disable capturing } \\
\text { device [202] } \\
\text { Virtual Walls [199] } \\
\text { Privacy-aware restricted areas [203] } \\
\text { PrivacyEye [204] } \\
\text { PrivacyVisor [205] } \\
\text { PrivacyVisor III [206] } \\
\text { Perturbed eyeglass frames [207] } \\
\text { Respectful cameras [208] } \\
\text { Negative face blurring [209] } \\
\text { FacePET [210] } \\
\text { I-Pic [211] }\end{array}$ \\
\hline $\begin{array}{l}\text { Access control } \\
\text { Location disclosure } \\
\text { Social implications } \\
\text { User's fear } \\
\text { Criminal abuse } \\
\text { Social media sync } \\
\text { Discrete display and visual } \\
\text { occlusion } \\
\text { Right to forget }\end{array}$ & $\begin{array}{l}\text { External } \\
\text { data-sharing } \\
\text { privacy }\end{array}$ & $\begin{array}{l}\text { k-anonymity [212] } \\
\text { l-diversity [213] } \\
\text { t-closeness [214] } \\
\text { Differential privacy }[215,216] \\
\text { Homomorphic encryption }[217,218]\end{array}$ \\
\hline
\end{tabular}

A second privacy issue with wearables is bystanders' privacy. Bystanders' privacy is the issue of the re-identification of third parties (bystanders) who have not provided consent when a sensing device is used in a bystander's surroundings [89]. Research in the area of bystanders' privacy has focused on understanding user and bystander privacy perceptions and privacy norms on the utilization of camera-enabled and voice-capturing devices in shared spaces [194,204,208,219-227] and on the development of systems for bystander privacy protection [200-211].

In the area of privacy perceptions and norms of camera-enabled and voice-capturing devices in shared spaces, past research has identified a conflict in spaces shared between users and bystanders [219,224,225,228], a desire of bystanders to have some control over what may be recorded and shared about them [220-222], and the meaning and definition of the contexts that affect the social meaning of privacy $[223,228]$. To protect bystanders privacy, research has focused on policies and systems to disable devices [200-204] and obfuscation of faces in photos in some systems [205-211].

Another privacy issue with wearables is external data sharing. When data are collected by remote services (such as systems described in Table 4), the issue of external data-sharing relates to how a remote service can protect a wearable's user privacy when shared with a third party. Third-party data-sharing can occur because of commercial agreements by which an external party provides some type of service on behalf of the remote service provider, or because the remote service provider sells the collected sensor data. Solutions that address this issue to protect the privacy of the collected data focus on anonymization methods in databases and cryptographic-based methods. 
Anonymization methods in databases protect wearable users' privacy by providing meaningful third-party data (in the statistical sense) without releasing data that can identify users. Depending on the kind of data to be released, these methods can be classified as methods for microdata release or methods for statistical data release [229]. In the first group (methods for microdata release), the goal is to protect users' private data by deidentifying private attributes of identities during the release of microdata (i.e., records from a database). Examples of methods for microdata release include k-anonymity [212], 1-diversity [213], and t-closeness [214]. In the second group (methods for statistical data release), we protect user privacy by guaranteeing that the release or calculation of a statistical result (such as an average) using collected data cannot reveal information about the specific records or a user. An example of a method that falls into this latter category is differential privacy $[215,216,230]$. A third class of methods available to protect data when externally shared is cryptographic-based methods, using homomorphic encryption techniques [217,218]. Homomorphic encryption allows a remote service provider to release data encrypted so that an external party can perform calculations on the encrypted data without revealing the original data or identifiable data.

\section{Challenges and Research Opportunities for Wearable Sensing Technologies}

In the previous sections, we reviewed the technological advances in various aspects of wearable sensing systems. Although significant work has been untertaken on wearable sensing systems in the last ten years, in this section, we identify areas of interest that need further research. These areas include security, privacy, 6G and ML at the edge (federated learning), energy harvesting and management, and interoperability.

\subsection{Security}

Even though we reviewed the vulnerabilities of and possible solutions for wearable technologies, security will continue to play an important role in the research and development and use of and trust in wearable devices. Attacks on wearables devices launched by an adversary can have catastrophic consequences for a user, especially if the wearable device is used in m-Health systems [158,231]. In addition, wearables connected to the Internet could be hacked and used to attack other systems. This creates the issue of developing wearables with a security-by-design paradigm $[232,233]$ to identify security risks and vulnerabilities during the design and development phases of a system rather than mitigating them after cyberattacks. The Mirai botnet illustrates this issue.

During late 2016, a distributed denial of service (DDoS) was launched over the Internet using a botnet called Mirai, which infected approximately 65,000 IoT devices such as DVR devices, IP cameras, routers, and printers [234]. Mirai converted them into zombies (i.e., devices controlled by a remote machine) and then used the infected IoT devices to launch various DDoS attacks on DNS servers. According to Antonakakis et al. [234], the attack was enabled by the design decisions of a small group of consumer electronics manufacturers. Although this attack used nonwearable IoTs, it underscores the need to incorporate security as part of the design process of a wearable. More research is needed to continue protecting current and next-generation wearables and mitigate emerging threats.

\subsection{Privacy}

One of the privacy challenges for users of wearable sensing technologies is making informed choices about the sensing devices that consumers buy and use. This highlights the importance of the development of usable privacy policies [235]. Privacy policies disclose the practices of remote services in terms of aspects such as data collection, management, and sharing about websites, services, and devices that consumers buy and use [144].

Although laws regarding the requirements of privacy policies and their content may differ from country to country, the General Data Protection Regulation (GDPR) regulation standardized these requirements for the European Union (EU) countries by mandating remote services to provide a privacy policy if these services control and process the personal 
data of individuals located in the EU, independent of the services being physically located in the EU or not [236]. However, companies whose markets may not be EU countries are not bound by this requirement, which may leave users in non-EU countries without an understanding of how remote services use with the data they collect through wearables. Furthermore, if privacy policies are provided, the accessibility and understandability of these privacy policies remain challenges. More research is needed on usable and practical privacy policies for wearables and for general IoT devices.

Another open privacy challenge for wearable sensing technologies is the control of users' sensor data collected by remote services and how data are shared with third parties (i.e., external systems or services) without users' consent. There are two aspects to this issue:the first is how the users know that their data are being shared with third parties (an issue related to privacy policies) and when this occurs; the second is how users' privacy may be protected when data are externally shared. While we reviewed solutions for the second issue, more work is needed to enable data-sharing with third parties while protecting users' privacy and allowing users to have control over their data.

Finally, bystanders' privacy [89] continues to be an open challenge in wearable devices. Even though we reviewed some solutions to address this issue, more research is needed to protect bystanders and to develop wearables with a focus on facial and voice privacy protection.

\section{3. $6 \mathrm{G}$ and Machine Learning at the Edge (Federated Learning)}

Currently, 5G networks continue to be deployed worldwide to support increasing mobile Internet traffic, including a growing demand for wearable sensing services [58]. However, the next generation of cellular networks (6G) will be designed to meet the demands of an intelligent, fully connected digital world $[237,238]$. It is expected that $6 \mathrm{G}$ networks will support pervasive and ubiquitous sensing services under very-low-latency requirements in the order of hundreds of microseconds [237]. To accomplish this, research is needed to integrate $\mathrm{AI}$ to dynamically predict traffic requirements, conduct adaptive and intelligent network management, and enhance remote sensing services.

Currently, remote services collect and store large amounts of wearable sensor data in clouds using machine learning (ML) and deep learning (DL) techniques to extract knowledge. Advances in graphical processing units (GPUs) have fueled a revolution in deep neural networks (DNNs) and DL by shortening the training time of DNN/DL models from months to hours. However, $6 \mathrm{G}$ networks will require part of this process to be conducted at edge devices (e.g., wearables, cellular phones, IoTs).

Federated learning (FL) [239] is a paradigm in ML/DL that is being investigated to train AI models using a decentralized process that is executed at edge devices. As ML/DL models in FL are trained at edge devices that collaborate among themselves rather than in centralized servers in a cloud (or data centers connected to the core of the Internet), less data are sent over the Internet, with advantages such as improved privacy, security, and access rights management. The resulting models built using FL can be as robust as models built using centralized ML/DL and are useful in areas such as telecommunications [240] and healthcare [241], amongst others. Additionally, research on techniques against adversarial ML, wherein wrong or fake data are used on purpose to make AI models fail, in FL environments is needed.

\subsection{Energy Harvesting and Management}

Advances in software, hardware, communication, computation, sensor technology, and AI have enabled the current generation of wearables; their power consumption will become increasingly important in the future. This will make energy harvesting and management one of the most important aspects that will drive the design and implementation of the next generation of wearables. Without power, a device cannot work, and one of the goals of using wearables is that a wearable device can continue performing its tasks 
without having to recharge, or if it needs to be recharged, it can be achieved in a way that is not cumbersome for its user (e.g., using wireless charging).

To improve energy management in wearables, hardware research should focus on the optimization of specific tasks of the wearable without relying on software. In particular, given the use of DL to classify and recognize wearable sensor data and the future use of FL to train ML models at the edge, hardware research can focus on alternate implementations of deep neural networks and other ML models to minimize power. Currently, FL algorithms may use high-power-consuming GPUs in battery-powered devices such as wearables to train distributed DL models, which may affect the usefulness of a wearable device [242,243]. An example of hardware-based optimization for DL models is the IBM Fusion chip [244], which can encode an artificial neural network analogically using phase-change memory (PCM) circuits performing classification without using a microprocessor, thus accelerating a classification task while minimizing power. Other areas of research include intelligent software management to predict power usage and to switch among different power profiles (software optimizations such as decreasing the clock rate frequency [43]) and harvesting techniques that can collect energy from a wearable's environment to enable its continuous operation.

A second aspect of energy management is the cost of energy needed to enable a wearable sensing system, from fabrication to operation and retirement or disposal. According to Smil [245], and using a concept called embodied energy (the sum of energy required to produce a good or service [246]), an approximation to the embodied energy of the production of all laptops, tablet, and mobile phones sold in 2015 was $1 \mathrm{EJ}\left(1 \times 10^{18}\right.$ Joules $)$ with an approximate weight of 550,000 metric tons; the 72 million cars sold during the same year accounted for 7 EJ of energy, while weighting about 100 million tons. According to his analysis, while the cars weighed 180 more times that of all portable electronics, they required only seven times as much energy to make [245]; while a car may last for a decade (or longer), many portable devices are disposed only after two years of operation. Cellular networks, which are needed for many future wearables, face a similar issue. In a research study, Humar et al. [247] found that embodied energy in cellular networks cannot be neglected because it accounts for an important and significant amount of their total energy consumption, and that embodied energy should be seriously considered in the design and development of other devices and systems used in the telecommunications sector (e.g., data centers). Thus, more work is needed to better estimate, optimize, and manage the energy consumption of telecommunication systems (such as wearable sensing systems) across their full lifecycle.

\subsection{Interoperability}

Wearable payment systems, fitness, and medical wearables are three of the fastestgrowing market segments of wearable services. While the financial payments industry has worked (since the early years of 2000) to make payment systems interoperable and secure through standards such as the Payment Application Data Security Standard (PADSS) $[16,248,249]$, this was not the case for fitness wearable services as of 2021.

On the fitness wearables side, the competition among many start-ups and wellestablished technological companies to position themselves as major players in the wearables market has made their wearable ecosystems closed ecosystems, with the exception of when a wearable/tech company takes over another wearable company (e.g., Google's Fitbit acquisition in 2021 for USD 2.1 billion [250]), or when a company partners through business deals with third parties, including insurance companies or employee wellness benefit services. For example, Virgin Pulse, as of October of 2021, was supporting eight wearable brands including Fitbit, Misfit, Garmin, Polar, Withings, MiBand (via VP Mobile App), Apple Watch (via VP Mobile App), and the Samsung Gear family (via VP Mobile App) [251]. Thus, which data can be shared among different systems is left to each company, which may hinder interoperability. On the medical wearables side (m-Health), the regulations to determine if a wearable is an approved medical device and what constitutes 
an electronic health record (EHR) varies from country to country [252,253]. For example, in the U.S., the process to approve a device for the purpose of medical diagnosis, cure, mitigation, and treatment of disease in humans or other animals is managed through the U.S. Food and Drug Administration (FDA/USFDA) [254]. Depending on the intrusiveness and risks to the human or animal, the device can fall into three classes (I being the lowest risk and III being the highest risk) and can take up approximately eight months to be FDAapproved. However, it can take much more time to document all the needed information for safety approval. For a wearable with connectivity (wired, wireless, or public Internet or intranet), the FDA submission should include a cybersecurity review of the device similar to the one described on the guidance document titled Content of Premarket Submissions for Management of Cybersecurity in Medical Devices [255]. A submitting organization can use a list of FDA-recognized cybersecurity consensus standards for IT and medical device security to document cybersecurity management. Table 8 presents these FDA-recognized standards (as of October 2021).

For EHR records in the U.S., if the data records generated by a medical device will be stored as part of an electronic health record (EHR), then different guidelines are used, which include the Health Insurance Portability and Accountability Act (HIPAA) and the Health Information Technology for Economic and Clinical Health (HITECH) Act. The largest companies in terms of market share developing software for EHR management tend to have closed networks (allowing sharing of EHRs easily only amongst network members of a specific company [256]), which has prompted the creation of alliances to share EHRs among smaller EHR software providers and practitioners (e.g., CommonWell Health Alliance [257]), lately as part of the U.S. Coronavirus Aid, Relief, and Economic Security Act (U.S. CARES Act) [258], giving hospitals and medical practitioners the option to use application programming interfaces (APIs) to exchange data using the recently developed United States Core Data for Interoperability (USCDI), which is a standardized set of health data classes and elements to allow interoperable exchange of health information nationwide. The second version of the USCDI was released in July 2021 [259].

While it is not mandated for fitness wearables companies to use medical-level standards, the latest development of standards for healthcare devices can provide interoperability among consumer wearables services in a secure and privacy-protected way, which may benefit users in the near future.

Table 8. U.S. FDA-recognized standards for medical informatics security.

\begin{tabular}{ccccl}
\hline FDA Date & FDA Number & Organization & $\begin{array}{c}\text { Organization } \\
\text { Designation/Date }\end{array}$ & Standard \\
\hline 7 June 2021 & $13-119$ & ANSI ISA & $62443-4-1-2018$ & $\begin{array}{l}\text { Security for industrial automation and control } \\
\text { systems Part 4-1: Product security development } \\
\text { life-cycle requirements. }\end{array}$ \\
\hline 7 June 2021 & 13-118 & IEEE & Std 11073-40102:2020 & $\begin{array}{l}\text { Health informatics-Device interoperability. Part } \\
\text { 40102: Foundational-Cybersecurity-Capabilities } \\
\text { for mitigation. }\end{array}$ \\
\hline 7 June 2021 & 13-117 & IEEE & Std 11073-40101-2020 & $\begin{array}{l}\text { Health informatics-Device interoperability Part } \\
\text { 40101: Foundational-Cybersecurity-Processes for } \\
\text { vulnerability assessment. }\end{array}$ \\
\hline 6 July 2020 & $13-115$ & IEC IEEE ISO & 29119-1 First edition & $\begin{array}{l}\text { Software and systems engineering-Software } \\
\text { testing-Part 1: Concepts and definitions }\end{array}$ \\
\hline 6 July 2020 & 13-114 & IEEE & Std 11073-10101-2019 & $\begin{array}{l}\text { Health informatics-Point-of-care medical device } \\
\text { communication. Part 10101: Nomenclature }\end{array}$ \\
\hline 23 December & 13-112 & AAMI & TIR97:2019 & $\begin{array}{l}\text { Principles for medical device security-Postmarket } \\
\text { risk management for device manufacturers }\end{array}$ \\
\hline
\end{tabular}


Table 8. Cont.

\begin{tabular}{|c|c|c|c|c|}
\hline FDA Date & FDA Number & Organization & $\begin{array}{c}\text { Organization } \\
\text { Designation/Date }\end{array}$ & Standard \\
\hline 15 July 2019 & 13-109 & AAMI ANSI UL & 2800-1: 2019 & $\begin{array}{l}\text { (American National Standard) Standard for } \\
\text { Safety for Medical Device Interoperability }\end{array}$ \\
\hline 7 June 2018 & $13-104$ & ANSI UL & $\begin{array}{l}\text { 2900-2-1 First Edition } \\
2017\end{array}$ & $\begin{array}{l}\text { Standard for Safety Software Cybersecurity for } \\
\text { Network-Connectable Products Part 2-1: } \\
\text { Particular Requirements for Network } \\
\text { Connectable Components of Healthcare and } \\
\text { Wellness Systems }\end{array}$ \\
\hline $\begin{array}{l}4 \text { December } \\
2017\end{array}$ & $13-103$ & IEC & $\begin{array}{l}\text { TR 80001-2-9 Edition } \\
1.02017-01\end{array}$ & $\begin{array}{l}\text { Application of risk management for IT-networks } \\
\text { incorporating medical devices-Part 2-9: } \\
\text { Application guidance-guidance for use of security } \\
\text { assurance cases to demonstrate confidence in IEC } \\
\text { TR } 80001-2-2 \text { security capabilities }\end{array}$ \\
\hline $\begin{array}{l}4 \text { December } \\
2017\end{array}$ & $13-102$ & IEC & $\begin{array}{l}\text { TR 80001-2-8 Edition } \\
1.02016-05\end{array}$ & $\begin{array}{l}\text { Application of risk management for IT-networks } \\
\text { incorporating medical devices-Part 2-8: } \\
\text { Application guidance-guidance on standards for } \\
\text { establishing the security capabilities identified in } \\
\text { IEC TR 80001-2-2 }\end{array}$ \\
\hline $\begin{array}{l}21 \text { August } \\
2017\end{array}$ & $13-97$ & IEC & $\begin{array}{l}\text { 82304-1 Edition } 1.0 \\
\text { 2016-10 }\end{array}$ & $\begin{array}{l}\text { Health software-Part 1: General requirements for } \\
\text { product safety }\end{array}$ \\
\hline $\begin{array}{l}21 \text { August } \\
2017\end{array}$ & $13-96$ & ANSI UL & $\begin{array}{l}\text { 2900-1 First Edition } \\
2017\end{array}$ & $\begin{array}{l}\text { Standard for Safety Standard for Software } \\
\text { Cybersecurity Network-Connectable Products } \\
\text { Part 1: General Requirements }\end{array}$ \\
\hline $\begin{array}{l}23 \text { December } \\
2016\end{array}$ & $13-85$ & CLSI & AUTO11-A2 & $\begin{array}{l}\text { Information Technology Security of In Vitro } \\
\text { Diagnostic Instruments and Software Systems; } \\
\text { Approved Standard-Second Edition }\end{array}$ \\
\hline 27 June 2016 & $13-83$ & AAMI & TIR57:2016 & $\begin{array}{l}\text { Principles for medical device security-Risk } \\
\text { management. }\end{array}$ \\
\hline $\begin{array}{l}14 \text { August } \\
2015\end{array}$ & $13-78$ & IEC ISO & $\begin{array}{l}30111 \text { First edition } \\
\text { 2013-11-01 }\end{array}$ & $\begin{array}{l}\text { Information technology-Security } \\
\text { techniques-Vulnerability handling processes }\end{array}$ \\
\hline $\begin{array}{l}14 \text { August } \\
2015\end{array}$ & $13-77$ & IEC ISO & $\begin{array}{l}29147 \text { First edition } \\
\text { 2014-02-15 }\end{array}$ & $\begin{array}{l}\text { Information technology-Security } \\
\text { techniques-Vulnerability disclosure }\end{array}$ \\
\hline $\begin{array}{l}\text { 27 January } \\
2015\end{array}$ & $13-70$ & IEC & $\begin{array}{c}\text { TR 80001-2-5 Edition } \\
1.02014-12\end{array}$ & $\begin{array}{l}\text { Application of risk management for IT-networks } \\
\text { incorporating medical devices-Part 2-5: } \\
\text { Application guidance-Guidance on distributed } \\
\text { alarm systems }\end{array}$ \\
\hline 6 August 2013 & $13-62$ & IEC & $\begin{array}{l}\text { TR 62443-3-1 Edition } \\
1.02009-07\end{array}$ & $\begin{array}{l}\text { Industrial communication networks-Network } \\
\text { and system security-Part 3-1: Security } \\
\text { technologies for industrial automation and } \\
\text { control systems }\end{array}$ \\
\hline 6 August 2013 & $13-61$ & IEC & $\begin{array}{l}\text { 62443-2-1 Edition } 1.0 \\
\text { 2010-11 }\end{array}$ & $\begin{array}{l}\text { Industrial communication networks-Network } \\
\text { and system security-Part 2-1: Establishing an } \\
\text { industrial automation and control system security } \\
\text { program }\end{array}$ \\
\hline 6 August 2013 & $13-60$ & IEC & $\begin{array}{c}\text { TS 62443-1-1 Edition } \\
1.02009-07\end{array}$ & $\begin{array}{l}\text { Industrial communication networks-Network } \\
\text { and system security-Part 1-1: Terminology } \\
\text { concepts and models }\end{array}$ \\
\hline 6 August 2013 & $13-44$ & IEC & $\begin{array}{l}\text { TR 80001-2-3 Edition } \\
1.02012-07\end{array}$ & $\begin{array}{l}\text { Application of risk management for IT Networks } \\
\text { incorporating medical devices-Part 2-3: Guidance } \\
\text { for wireless networks }\end{array}$ \\
\hline
\end{tabular}


Table 8. Cont.

\begin{tabular}{ccccc}
\hline FDA Date & FDA Number & Organization & $\begin{array}{c}\text { Organization } \\
\text { Designation/Date }\end{array}$ & Standard \\
\hline 6 August 2013 & $13-42$ & IEC & $\begin{array}{c}\text { TR 80001-2-2 Edition } \\
1.0 \text { 2012-07 }\end{array}$ & $\begin{array}{c}\text { Application of risk management for IT Networks } \\
\text { incorporating medical devices-Part 2-2: Guidance } \\
\text { for the disclosure and communication of medical } \\
\text { device security needs risks and controls }\end{array}$ \\
\hline 6 August 2013 & $13-38$ & IEC & $\begin{array}{c}80001-1 \text { Edition 1.0 } \\
\text { 2010-10 }\end{array}$ & $\begin{array}{l}\text { Application of risk management for IT-networks } \\
\text { incorporating medical devices-Part 1: Roles } \\
\text { responsibilities and activities }\end{array}$ \\
\hline
\end{tabular}

\section{Conclusions}

Over the last few decades, we have witnessed significant developments in the design and deployment of wearable sensing technologies. The size and cost of these technologies continue to decrease while their performance and capabilities continue to improve, making them increasingly pervasive in a wide range of applications. We foresee that wearable sensing technologies and services will continue to be improved and deployed worldwide in the future. In this work, we reviewed technological advances that have made wearable sensing possible and affordable. We described different types of wearable sensors, communication and remote services technologies, and security and privacy issues related to wearable devices. We also reviewed the use of consumer wearables during the COVID-19 pandemic caused by SARS-CoV-2. Finally, we discussed research challenges that must be addressed to further improve wearable sensing systems in terms of their designs, energy consumption, security, privacy, and interoperability.

In this review, we did not discuss the extensive use of different types of sensors that track human behaviors (e.g., movements of elderly people or flexing a finger) for different types of users in various types of environments, the safety of wearable sensors (we only presented a summary of FDA-approved standards), integration issues with body area networks (BANs) with other emerging technologies (e.g., fog, edge, and 6G), or AI-enabled sensors that could play a pivotal role in future medical services. In the future, we will explore some of these issues.

Author Contributions: Conceptualization, A.J.P. and S.Z.; investigation, A.J.P. and S.Z.; writingoriginal draft preparation, A.J.P. and S.Z.; writing—review and editing, A.J.P. and S.Z. All authors have read and agreed to the published version of the manuscript.

Funding: This research was funded by the U.S. National Science Foundation under grant award No. 1950416.

Acknowledgments: We thank the anonymous reviewers for their valuable comments, which helped improve the paper's content, quality, and organization. Alfredo J. Perez dedicates this work to the memory of Freddy Perez-Bossa and Miguel A. Labrador.

Conflicts of Interest: The authors declare no conflict of interest. The funders had no role in the design of the study; in the collection, analyses, or interpretation of data; in the writing of the manuscript; or in the decision to publish the results. 


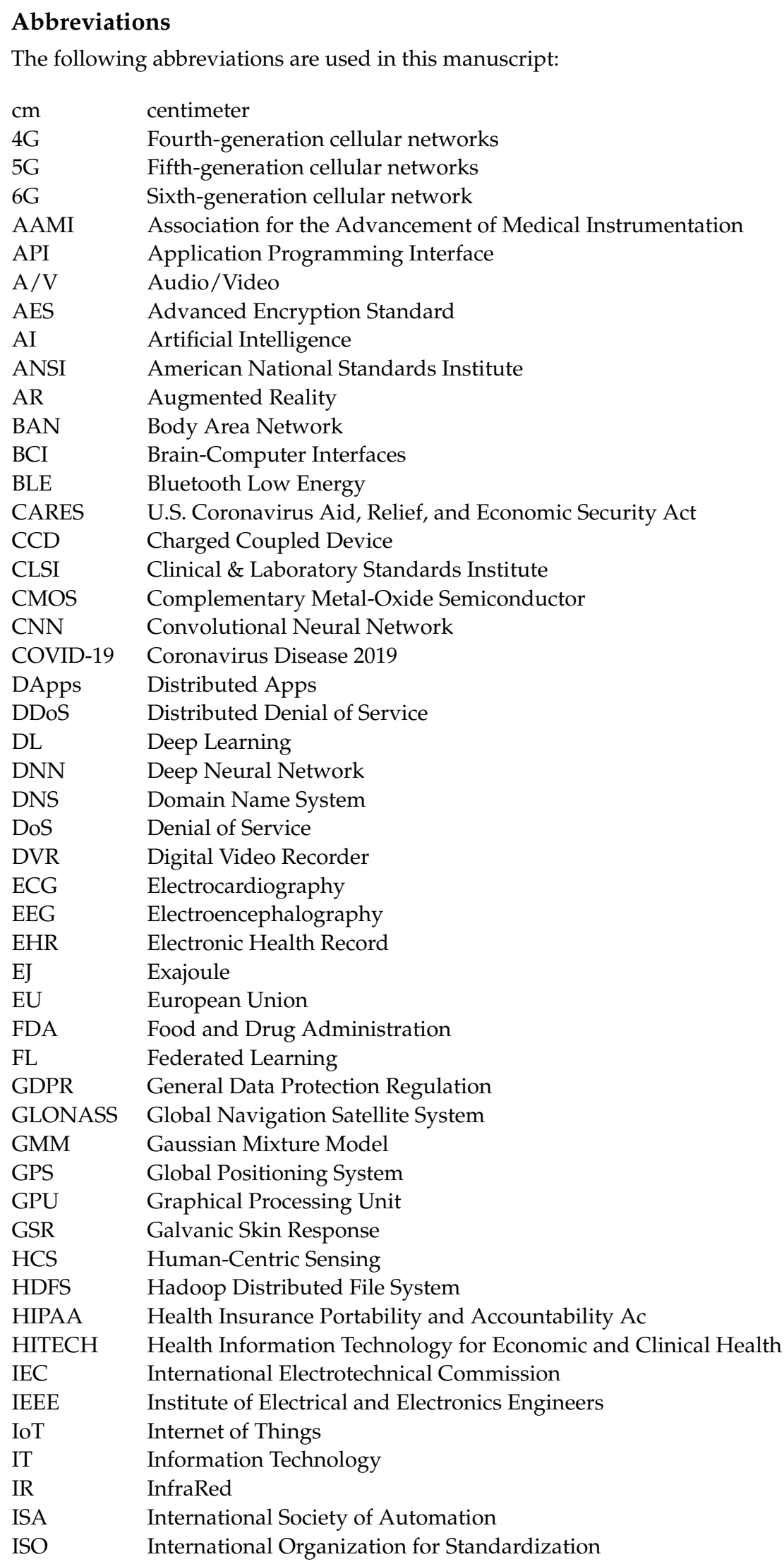




$\begin{array}{ll}\text { LAN } & \text { Local Area Network } \\ \text { LBS } & \text { Location-Based Services } \\ \text { LiDAR } & \text { Light Detection And Ranging } \\ \text { LSTM } & \text { Long Short-Term Memory } \\ \text { MAC } & \text { Medium Access Control } \\ \text { MANET } & \text { Mobile Adhoc NETworks } \\ \text { MEMS } & \text { Microelectromechanical Systems } \\ \text { m-Health } & \text { Mobile Health } \\ \text { MITM } & \text { Man In the Middle } \\ \text { ML } & \text { Machine Learning } \\ \text { MRF } & \text { Markov Random Field } \\ \text { NFC } & \text { Near-Field Communication } \\ \text { NN } & \text { Neural Network } \\ \text { OS } & \text { Operating System } \\ \text { PA-DSS } & \text { Payment Application Data Security Standard } \\ \text { PAN } & \text { Personal Area Network } \\ \text { PB } & \text { Petabytes } \\ \text { PCA } & \text { Principal Component Analysis } \\ \text { PCM } & \text { Phase-Change Memory } \\ \text { PPG } & \text { Photoplethysmography } \\ \text { PS/CS } & \text { Participatory/Crowdsensing Systems } \\ \text { PV } & \text { Photovoltaic } \\ \text { RF } & \text { Radiofrequency } \\ \text { RFID } & \text { Radiofrequency Identification } \\ \text { SARS-CoV-2 } & \text { Severe Acute Respiratory Syndrome Coronavirus 2 } \\ \text { SQL } & \text { Structured Query Language } \\ \text { SVM } & \text { Support Vector Machine } \\ \text { TCP/IP } & \text { Transmission Control Protocol/Internet Protocol } \\ \text { TWS } & \text { True Wireless Stereo } \\ \text { UL } & \text { UL Incorporated, previously known as Underwriters Laboratories } \\ \text { USD } & \text { US Dollars } \\ \text { USFDA } & \text { US Food and Drug Administration } \\ \text { WLAN } & \text { Wireless Local Area Network } \\ \text { WSN } & \text { Wireless Sensor Network } \\ \text { WWAN } & \text { Wireless Wide Area Network } \\ & \end{array}$

\section{References}

1. Hayward, J. Wearable Technology Forecasts 2021-2031. Available online: https://www.idtechex.com/en/research-report/ wearable-technology-forecasts-2021-2031/839 (accessed on 26 September 2021).

2. Gartner Forecasts Global Spending on Wearable Devices to Total $\$ 81.5$ Billion in 2021. Available online: https: / /www.gartner. $\mathrm{com} / \mathrm{en} /$ newsroom/press-releases /2021-01-11-gartner-forecasts-global-spending-on-wearable-devices-to-total-81-5-billionin-2021 (accessed on 26 September 2021).

3. Lee, L. Global TWS Hearables Market Tracker and Analysis: Q2 2021. Available online: https://report.counterpointresearch. com/posts/report_view/Emerging_Tech/2452 (accessed on 26 September 2021).

4. De Sio, L.; Ding, B.; Focsan, M.; Kogermann, K.; Pascoal-Faria, P.; Petronela, F.; Mitchell, G.; Zussman, E.; Pierini, F. Personalized Reusable Face Masks with Smart Nano-Assisted Destruction of Pathogens for COVID-19: A Visionary Road. Chem. A Eur. J. 2021, 27, 6112-6130. [CrossRef]

5. Razer. Project Hazel. Available online: https://www.razer.com/concepts/razer-project-hazel (accessed on 1 October 2021).

6. UVMask. UVMask. Available online: https://uvmask.com/ (accessed on 1 October 2021).

7. Trafton, A. New Face Mask Prototype Can Detect Covid-19 Infection. Available online: https://news.mit.edu/2021/face-maskcovid-19-detection-0628 (accessed on 1 October 2021).

8. Nguyen, P.Q.; Soenksen, L.R.; Donghia, N.M.; Angenent-Mari, N.M.; de Puig, H.; Huang, A.; Lee, R.; Slomovic, S.; Galbersanini, T.; Lansberry, G.; et al. Wearable materials with embedded synthetic biology sensors for biomolecule detection. Nat. Biotechnol. 2021, 1-9. [CrossRef]

9. Ahmed, N.; Michelin, R.A.; Xue, W.; Ruj, S.; Malaney, R.; Kanhere, S.S.; Seneviratne, A.; Hu, W.; Janicke, H.; Jha, S.K. A survey of COVID-19 contact tracing apps. IEEE Access 2020, 8, 134577-134601. [CrossRef]

10. Drew, D.A.; Nguyen, L.H.; Steves, C.J.; Menni, C.; Freydin, M.; Varsavsky, T.; Sudre, C.H.; Cardoso, M.J.; Ourselin, S.; Wolf, J.; et al. Rapid implementation of mobile technology for real-time epidemiology of COVID-19. Science 2020, 368, 1362-1367. [CrossRef] 
11. Cho, H.; Ippolito, D.; Yu, Y.W. Contact tracing mobile apps for COVID-19: Privacy considerations and related trade-offs. arXiv 2020, arXiv:2003.11511.

12. Wright, J.H.; Caudill, R. Remote treatment delivery in response to the COVID-19 pandemic. Psychother. Psychosom. 2020, 89, 1. [CrossRef] [PubMed]

13. Markets\&Markets. Knowledge Store Interactive Wearable Dashboard. Available online: https://www.mnmks.com/demo/ pages/mega_trends/wearable (accessed on 28 September 2021).

14. Marketwatch. Fitness Tracker Market 2021 Global impact of COVID-19 on Size, Share, Trends, Historical Analysis, Opportunities and Industry Segments Poised for Rapid Growth by 2026. Available online: https://tinyurl.com/bwrd6efb (accessed on 28 September 2021).

15. Wearable Fitness Tracker Market Research Report by Display Type, by Device Type, by Operating System, by Distribution-Global Forecast to 2025-Cumulative Impact of COVID-19. Available online: https: / www.yahoo.com/now/wearable-fitness-trackermarket-research-130900948.html (accessed on 28 September 2021).

16. Secure Technology Alliance. Contactless Payments Resources. Available online: https://www.securetechalliance.org/activitiescouncils-contactless-payments-resources (accessed on 1 October 2021).

17. Téllez, J.; Zeadally, S. Mobile Payment Systems: Secure Network Architectures and Protocols; Springer: Berlin/Heidelberg, Germany, 2017.

18. Bello, G.; Perez, A.J. Adapting financial technology standards to blockchain platforms. In Proceedings of the 2019 ACM Southeast Conference, Kennesaw, GA, USA, 18-20 April 2019; pp. 109-116.

19. NFC Ring. Available online: https://nfcring.com/ (accessed on 28 September 2021).

20. GVR. Fitness Tracker Market Size Worth \$138.7 Billion By 2028 I CAGR: 18.9\%. Available online: https://tinyurl.com/bunfepdy (accessed on 28 September 2021).

21. GVR. Wearable Payments Devices Market Size, Share \& Trends Analysis Report by Device Type (Fitness Tracker, Smart Watches), by Technology, By Application, by Region, and Segment Forecasts, 2021-2028. Available online: https:/ /www.grandviewresearch. com/industry-analysis / wearable-payments-devices-market (accessed on 28 September 2021).

22. VMR. Fitness Tracker Market Size And Forecast. Available online: https://www.verifiedmarketresearch.com/product/fitnesstracker-market/ (accessed on 28 September 2021).

23. Perez, A.J.; Labrador, M.A.; Barbeau, S.J. G-sense: A scalable architecture for global sensing and monitoring. IEEE Netw. 2010, 24, 57-64. [CrossRef]

24. Lane, N.D.; Miluzzo, E.; Lu, H.; Peebles, D.; Choudhury, T.; Campbell, A.T. A survey of mobile phone sensing. IEEE Commun. Mag. 2010, 48, 140-150. [CrossRef]

25. Christin, D.; Reinhardt, A.; Kanhere, S.S.; Hollick, M. A survey on privacy in mobile participatory sensing applications. J. Syst. Softw. 2011, 84, 1928-1946. [CrossRef]

26. Lara, O.D.; Labrador, M.A. A survey on human activity recognition using wearable sensors. IEEE Commun. Surv. Tutor. 2012, 15, 1192-1209. [CrossRef]

27. Khan, W.Z.; Xiang, Y.; Aalsalem, M.Y.; Arshad, Q. Mobile phone sensing systems: A survey. IEEE Commun. Surv. Tutor. 2012, 15, 402-427. [CrossRef]

28. Macias, E.; Suarez, A.; Lloret, J. Mobile sensing systems. Sensors 2013, 13, 17292-17321. [CrossRef] [PubMed]

29. Park, S.; Chung, K.; Jayaraman, S. Wearables: Fundamentals, advancements, and a roadmap for the future. In Wearable Sensors; Elsevier: Amsterdam, The Netherlands, 2014; pp. 1-23.

30. Jaimes, L.G.; Vergara-Laurens, I.J.; Raij, A. A survey of incentive techniques for mobile crowd sensing. IEEE Internet Things J. 2015, 2, 370-380. [CrossRef]

31. Merlo, A.; Migliardi, M.; Caviglione, L. A survey on energy-aware security mechanisms. Pervasive Mob. Comput. 2015, 24, 77-90. [CrossRef]

32. Bellekens, X.; Hamilton, A.; Seeam, P.; Nieradzinska, K.; Franssen, Q.; Seeam, A. Pervasive eHealth services a security and privacy risk awareness survey. In Proceedings of the 2016 International Conference On Cyber Situational Awareness, Data Analytics And Assessment (CyberSA), London, UK, 13-14 June 2016; pp. 1-4.

33. Restuccia, F.; Das, S.K.; Payton, J. Incentive mechanisms for participatory sensing: Survey and research challenges. ACM Trans. Sens. Netw. (TOSN) 2016, 12, 1-40. [CrossRef]

34. Hammerla, N.Y.; Halloran, S.; Plötz, T. Deep, Convolutional, and Recurrent Models for Human Activity Recognition Using Wearables. In Proceedings of the Twenty-Fifth International Joint Conference on Artificial Intelligence, New York, NY, USA, 9-15 July 2016; pp. 1-4.

35. Seneviratne, S.; Hu, Y.; Nguyen, T.; Lan, G.; Khalifa, S.; Thilakarathna, K.; Hassan, M.; Seneviratne, A. A survey of wearable devices and challenges. IEEE Commun. Surv. Tutor. 2017, 19, 2573-2620. [CrossRef]

36. Tana, J.; Forss, M.; Hellsten, T. The Use of Wearables in Healthcare-Challenges and Opportunities. Available online: https: //www.theseus.fi/handle/10024/140584 (accessed on 5 October 2021).

37. Qiu, H.; Wang, X.; Xie, F. A survey on smart wearables in the application of fitness. In Proceedings of the 2017 IEEE 15 th International Conference on Dependable, Autonomic and Secure Computing, 15th International Conference on Pervasive Intelligence and Computing, 3rd International Conference on Big Data Intelligence and Computing and Cyber Science and Technology Congress (DASC/PiCom/DataCom/CyberSciTech), Orlando, FL, USA, 6-10 November 2017; pp. $303-307$. 
38. Perez, A.J.; Zeadally, S. Privacy issues and solutions for consumer wearables. Professional 2017, 20, 46-56. [CrossRef]

39. Peake, J.M.; Kerr, G.; Sullivan, J.P. A critical review of consumer wearables, mobile applications, and equipment for providing biofeedback, monitoring stress, and sleep in physically active populations. Front. Physiol. 2018, 9, 743. [CrossRef]

40. Dunn, J.; Runge, R.; Snyder, M. Wearables and the medical revolution. Pers. Med. 2018, 15, 429-448. [CrossRef] [PubMed]

41. Neshenko, N.; Bou-Harb, E.; Crichigno, J.; Kaddoum, G.; Ghani, N. Demystifying IoT security: An exhaustive survey on IoT vulnerabilities and a first empirical look on Internet-scale IoT exploitations. IEEE Commun. Surv. Tutor. 2019, 21, 2702-2733. [CrossRef]

42. Van Der Linden, D.; Zamansky, A.; Hadar, I.; Craggs, B.; Rashid, A. Buddy's wearable is not your buddy: Privacy implications of pet wearables. IEEE Secur. Priv. 2019, 17, 28-39. [CrossRef]

43. Zeadally, S.; Shaikh, F.K.; Talpur, A.; Sheng, Q.Z. Design architectures for energy harvesting in the Internet of Things. Renew. Sustain. Energy Rev. 2020, 128, 109901. [CrossRef]

44. Niknejad, N.; Ismail, W.B.; Mardani, A.; Liao, H.; Ghani, I. A comprehensive overview of smart wearables: The state of the art literature, recent advances, and future challenges. Eng. Appl. Artif. Intell. 2020, 90, 103529. [CrossRef]

45. Díaz, S.; Stephenson, J.B.; Labrador, M.A. Use of wearable sensor technology in gait, balance, and range of motion analysis. Appl. Sci. 2020, 10, 234. [CrossRef]

46. Dian, F.J.; Vahidnia, R.; Rahmati, A. Wearables and the Internet of Things (IoT), applications, opportunities, and challenges: A Survey. IEEE Access 2020, 8, 69200-69211. [CrossRef]

47. Svertoka, E.; Saafi, S.; Rusu-Casandra, A.; Burget, R.; Marghescu, I.; Hosek, J.; Ometov, A. Wearables for Industrial Work Safety: A Survey. Sensors 2021, 21, 3844. [CrossRef] [PubMed]

48. Ometov, A.; Shubina, V.; Klus, L.; Skibińska, J.; Saafi, S.; Pascacio, P.; Flueratoru, L.; Gaibor, D.Q.; Chukhno, N.; Chukhno, O.; et al. A survey on wearable technology: History, state-of-the-art and current challenges. Comput. Netw. 2021, 193, 108074. [CrossRef]

49. The Wearables Database. Available online: https://vandrico.com/wearables.html (accessed on 17 September 2021).

50. Ramokapane, K.M.; van der Linden, D.; Zamansky, A. Does my dog really need a gadget? What can we learn from pet owners' amotivations for using pet wearables? In Proceedings of the Sixth International Conference on Animal-Computer Interaction, Haifa, Israel, 12-14 November 2019; pp. 1-6.

51. Kiourti, A.; Nikita, K.S. A review of in-body biotelemetry devices: Implantables, ingestibles, and injectables. IEEE Trans. Biomed. Eng. 2017, 64, 1422-1430. [CrossRef] [PubMed]

52. Dias, T. Electronic Textiles: Smart Fabrics and Wearable Technology; Woodhead Publishing: Sawston, UK, 2015.

53. Castaneda, D.; Esparza, A.; Ghamari, M.; Soltanpur, C.; Nazeran, H. A review on wearable photoplethysmography sensors and their potential future applications in health care. Int. J. Biosens. Bioelectron. 2018, 4, 195. [PubMed]

54. Ghosh, S.; Bose, M.; Kudeshia, A. GPS and GSM Enabled Smart Blind Stick. In Proceedings of the International Conference on Communication, Circuits, and Systems 2020, Bhubaneswar, Odisha, India, 16-20 October 2020; pp. 179-185.

55. Eckart, R.E.; Kinney, K.G.; Belnap, C.M.; Le, T.D. Ventricular fibrillation refractory to automatic internal cardiac defibrillator in Fabry's disease. Cardiology 2000, 94, 208-212. [CrossRef]

56. Prausnitz, M.R.; Langer, R. Transdermal drug delivery. Nat. Biotechnol. 2008, 26, 1261-1268. [CrossRef] [PubMed]

57. Sharma, R.; Singh, D.; Gaur, P.; Joshi, D. Intelligent automated drug administration and therapy: Future of healthcare. Drug Deliv. Transl. Res. 2021, 1-25.

58. Ericsson. Ericsson Mobility Report. Available online: https://www.ericsson.com/en/mobility-report (accessed on 17 September 2021).

59. BlueBite. The State of NFC in 2021. Available online: https://www.bluebite.com/nfc/nfc-usage-statistics (accessed on 1 October 2021).

60. Stables, J. Wearables Popularity Soars in 2020-And Huawei Is the Big Winner. Available online: https://www.wareable.com/ news / wearables-popularity-soars-in-2020-8322 (accessed on 1 October 2021).

61. Statistica. Unit Sales of True Wireless Hearables Worldwide from 2018 to 2021. Available online: https://www.statista.com/ statistics/985608/worldwide-sales-volume-true-wireless-hearables / (accessed on 1 October 2021).

62. Henriksen, A.; Mikalsen, M.H.; Woldaregay, A.Z.; Muzny, M.; Hartvigsen, G.; Hopstock, L.A.; Grimsgaard, S. Using fitness trackers and smartwatches to measure physical activity in research: Analysis of consumer wrist-worn wearables. J. Med. Internet Res. 2018, 20, e9157. [CrossRef]

63. Vasudevan, R.S.; Horiuchi, Y.; Torriani, F.J.; Cotter, B.; Maisel, S.M.; Dadwal, S.S.; Gaynes, R.; Maisel, A.S. Persistent Value of the Stethoscope in the Age of COVID-19. Am. J. Med. 2020, 133, 1143-1150. [CrossRef]

64. Hammond, R. A Pilot Study on the Validity and Reliability of Portable Ultrasound Assessment of Swallowing with Dysphagic Patients. Master's Thesis, University of Canterbury, Canterbury, Australia, 2019.

65. Jokic, P.; Magno, M. Powering smart wearable systems with flexible solar energy harvesting. In Proceedings of the 2017 IEEE International Symposium on Circuits and Systems (ISCAS), Baltimore, MD, USA, 28-31 May 2017; pp. 1-4.

66. Aubert, H. RFID technology for human implant devices. Comptes Rendus Phys. 2011, 12, 675-683. [CrossRef]

67. Alberto, J.; Leal, C.; Fernandes, C.; Lopes, P.A.; Paisana, H.; de Almeida, A.T.; Tavakoli, M. Fully untethered battery-free biomonitoring electronic tattoo with wireless energy harvesting. Sci. Rep. 2020, 10, 1-11. [CrossRef] [PubMed]

68. González, J.L.; Rubio, A.; Moll, F. Human powered piezoelectric batteries to supply power to wearable electronic devices. Int. J. Soc. Mater. Eng. Resour. 2002, 10, 34-40. [CrossRef] 
69. Radziemski, L.; Makin, I.R.S. In vivo demonstration of ultrasound power delivery to charge implanted medical devices via acute and survival porcine studies. Ultrasonics 2016, 64, 1-9. [CrossRef] [PubMed]

70. Manjarres, J.; Pardo, M. An Energy Logger for Kinetic-Powered Wrist-Wearable Systems. Electronics 2020, 9, 487. [CrossRef]

71. Francioso, L.; De Pascali, C.; Farella, I.; Martucci, C.; Cretì, P.; Siciliano, P.; Perrone, A. Flexible thermoelectric generator for ambient assisted living wearable biometric sensors. J. Power Sources 2011, 196, 3239-3243. [CrossRef]

72. Hyland, M.; Hunter, H.; Liu, J.; Veety, E.; Vashaee, D. Wearable thermoelectric generators for human body heat harvesting. Appl. Energy 2016, 182, 518-524. [CrossRef]

73. Castano, L.M.; Flatau, A.B. Smart fabric sensors and e-textile technologies: A review. Smart Mater. Struct. 2014, $23,053001$. [CrossRef]

74. Ondrus, J.; Pigneur, Y. An assessment of NFC for future mobile payment systems. In Proceedings of the International Conference on the Management of Mobile Business (ICMB 2007), Toronto, ON, Canada, 9-11 July 2007; p. 43.

75. Kulkarni, R. Near Field Communication (NFC) Technology and Its Application. Techno-Societal 2021, 2020, 745-751.

76. Wilder, V.T.; Gao, Y.; Wang, S.P.; Perez, A.J. Multi-Factor Stateful Authentication using NFC, and Mobile Phones. In Proceedings of the 2019 SoutheastCon, Huntsville, AL, USA, 11-14 April 2019; pp. 1-6.

77. Picard, R.W.; Vyzas, E.; Healey, J. Toward machine emotional intelligence: Analysis of affective physiological state. IEEE Trans. Pattern Anal. Mach. Intell. 2001, 23, 1175-1191. [CrossRef]

78. Hwang, S.; Seo, J.; Jebelli, H.; Lee, S. Feasibility analysis of heart rate monitoring of construction workers using a photoplethysmography (PPG) sensor embedded in a wristband-type activity tracker. Autom. Constr. 2016, 71, 372-381. [CrossRef]

79. Perez, A.J.; Rivera-Morales, K.G.; Labrador, M.A.; Vergara-Laurens, I. HR-auth: Heart rate data authentication using consumer wearables. In Proceedings of the 2018 IEEE/ ACM 5th International Conference on Mobile Software Engineering and Systems (MOBILESoft), Gothenburg, Sweden, 27-28 May 2018; pp. 88-89.

80. Lee, H.; Kim, E.; Lee, Y.; Kim, H.; Lee, J.; Kim, M.; Yoo, H.J.; Yoo, S. Toward all-day wearable health monitoring: An ultralowpower, reflective organic pulse oximetry sensing patch. Sci. Adv. 2018, 4, eaas9530. [CrossRef]

81. Fortino, G.; Giampà, V. PPG-based methods for non invasive and continuous blood pressure measurement: An overview and development issues in body sensor networks. In Proceedings of the 2010 IEEE International Workshop on Medical Measurements and Applications, Ottawa, ON, Canada, 30 April-1 May 2010; pp. 10-13.

82. Lau-Zhu, A.; Lau, M.P.; McLoughlin, G. Mobile EEG in research on neurodevelopmental disorders: Opportunities and challenges. Dev. Cogn. Neurosci. 2019, 36, 100635. [CrossRef]

83. Abiri, R.; Borhani, S.; Sellers, E.W.; Jiang, Y.; Zhao, X. A comprehensive review of EEG-based brain-computer interface paradigms. J. Neural Eng. 2019, 16, 011001. [CrossRef] [PubMed]

84. The Juvenile Diabetes Research Foundation Continuous Glucose Monitoring Study Group. Continuous glucose monitoring and intensive treatment of type diabetes. N. Engl. J. Med. 2008, 359, 1464-1476. [CrossRef] [PubMed]

85. Lara, O.D.; Pérez, A.J.; Labrador, M.A.; Posada, J.D. Centinela: A human activity recognition system based on acceleration and vital sign data. Pervasive Mob. Comput. 2012, 8, 717-729. [CrossRef]

86. Laput, G.; Ahuja, K.; Goel, M.; Harrison, C. Ubicoustics: Plug-and-play acoustic activity recognition. In Proceedings of the 31st Annual ACM Symposium on User Interface Software and Technology, Berlin, Germany, 14-17 October 2018; pp. $213-224$.

87. Labrador, M.A.; Perez, A.J.; Wightman, P.M. Location-Based Information Systems: Developing Real-Time Tracking Applications; CRC Press: Boca Raton, FL, USA, 2010.

88. Basiri, A.; Lohan, E.S.; Moore, T.; Winstanley, A.; Peltola, P.; Hill, C.; Amirian, P.; e Silva, P.F. Indoor location based services challenges, requirements and usability of current solutions. Comput. Sci. Rev. 2017, 24, 1-12. [CrossRef]

89. Perez, A.J.; Zeadally, S.; Griffith, S. Bystanders' privacy. IT Prof. 2017, 19, 61-65. [CrossRef]

90. Weinstein, R. RFID: A technical overview and its application to the enterprise. IT Prof. 2005, 7, 27-33. [CrossRef]

91. Perez, A.J.; Zeadally, S. A communication architecture for crowd management in emergency and disruptive scenarios. IEEE Commun. Mag. 2019, 57, 54-60. [CrossRef]

92. Stein, S. Lidar Is One of the iPhone and iPad's Coolest Tricks. Here's What Else It Can Do. Available online: https://www.cnet. $\mathrm{com} /$ tech/mobile/lidar-is-one-of-the-iphone-ipad-coolest-tricks-its-only-getting-better/ (accessed on 17 September 2021).

93. White, P.F.; Lazo, O.L.E.; Galeas, L.; Cao, X. Use of electroanalgesia and laser therapies as alternatives to opioids for acute and chronic pain management. F1000Research 2017, 6, 2161. [CrossRef] [PubMed]

94. Asad, S.; Mooney, B.; Ahmad, I.; Huber, M.; Clark, A. Object detection and sensory feedback techniques in building smart cane for the visually impaired: An overview. In Proceedings of the 13th ACM International Conference on PErvasive Technologies Related to Assistive Environments (PETRA), Corfu, Greece, 30 June-3 July 2020; pp. 1-7.

95. Mendez, D.; Perez, A.J.; Labrador, M.A.; Marron, J.J. P-sense: A participatory sensing system for air pollution monitoring and control. In Proceedings of the 2011 IEEE International Conference on Pervasive Computing and Communications Workshops (PERCOM Workshops), Seattle, WA, USA, 21-25 March 2011; pp. 344-347.

96. Das, A.J.; Wahi, A.; Kothari, I.; Raskar, R. Ultra-portable, wireless smartphone spectrometer for rapid, non-destructive testing of fruit ripeness. Sci. Rep. 2016, 6, 1-8. [CrossRef]

97. Dhanekar, S.; Rangra, K. Wearable Dosimeters for Medical and Defence Applications: A State of the Art Review. Adv. Mater. Technol. 2021, 6, 2000895. [CrossRef] 
98. Vanveerdeghem, P.; Van Torre, P.; Thielens, A.; Knockaert, J.; Joseph, W.; Rogier, H. Compact personal distributed wearable exposimeter. IEEE Sens. J. 2015, 15, 4393-4401. [CrossRef]

99. Masse, F.; Gonzenbach, R.; Paraschiv-Ionescu, A.; Luft, A.R.; Aminian, K. Wearable barometric pressure sensor to improve postural transition recognition of mobility-impaired stroke patients. IEEE Trans. Neural Syst. Rehabil. Eng. 2016, 24, $1210-1217$. [CrossRef]

100. Makma, J.; Thanapatay, D.; Isshiki, T.; Chinrungrueng, J.; Thiemjarus, S. Enhancing Accelerometer-based Human Activity Recognition with Relative Barometric Pressure Signal. In Proceedings of the 2021 18th International Conference on Electrical Engineering/Electronics, Computer, Telecommunications and Information Technology (ECTI-CON), Chiang Mai, Thailand, 19-22 May 2021; pp. 529-532.

101. Seyedi, M.; Kibret, B.; Lai, D.T.; Faulkner, M. A survey on intrabody communications for body area network applications. IEEE Trans. Biomed. Eng. 2013, 60, 2067-2079. [CrossRef]

102. Zeadally, S.; Siddiqui, F.; Baig, Z. 25 years of Bluetooth technology. Future Internet 2019, 11, 194. [CrossRef]

103. Negra, R.; Jemili, I.; Belghith, A. Wireless body area networks: Applications and technologies. Procedia Comput. Sci. 2016, 83, 1274-1281. [CrossRef]

104. Liu, Y.H.; Huang, X.; Vidojkovic, M.; Ba, A.; Harpe, P.; Dolmans, G.; de Groot, H. A 1.9 nJ/b 2.4 GHz multistandard (Bluetooth Low Energy/Zigbee/IEEE802. 15.6) transceiver for personal/body-area networks. In Proceedings of the 2013 IEEE International Solid-State Circuits Conference Digest of Technical Papers, San Francisco, CA, USA, 17-21 February 2013; pp. $446-447$.

105. Kwak, K.S.; Ullah, S.; Ullah, N. An overview of IEEE 802.15. 6 standard. In Proceedings of the 2010 3rd International Symposium on Applied Sciences in Biomedical and Communication Technologies (ISABEL 2010), Rome, Italy, 7-10 November 2010; pp. 1-6.

106. Coskun, V.; Ozdenizci, B.; Ok, K. A survey on near field communication (NFC) technology. Wirel. Pers. Commun. 2013, 71, 2259-2294. [CrossRef]

107. Company, T.S. Sensium Wireless Vitals Monitoring. Available online: https://www.sensium.co.uk/us/ (accessed on 17 September 2021).

108. ANT Basics. Available online: https://www.thisisant.com/developer/ant/ant-basics/ (accessed on 17 September 2021).

109. NFC Market. Available online: https://www.marketsandmarkets.com/Market-Reports/near-field-communication-nfc-market520.html (accessed on 1 October 2021).

110. Gabriel, S.; Lau, R.; Gabriel, C. The dielectric properties of biological tissues: III. Parametric models for the dielectric spectrum of tissues. Phys. Med. Biol. 1996, 41, 2271. [CrossRef] [PubMed]

111. Suda, T.; Moore, M.; Nakano, T.; Egashira, R.; Enomoto, A.; Hiyama, S.; Moritani, Y. Exploratory research on molecular communication between nanomachines. In Proceedings of the Genetic and Evolutionary Computation Conference (GECCO), Washington DC, USA, 25-29 June 2005; Volume 25, p. 29.

112. Pierobon, M.; Akyildiz, I.F. A physical end-to-end model for molecular communication in nanonetworks. IEEE J. Sel. Areas Commun. 2010, 28, 602-611. [CrossRef]

113. Farsad, N.; Yilmaz, H.B.; Eckford, A.; Chae, C.B.; Guo, W. A comprehensive survey of recent advancements in molecular communication. IEEE Commun. Surv. Tutor. 2016, 18, 1887-1919. [CrossRef]

114. Galluccio, L.; Melodia, T.; Palazzo, S.; Santagati, G.E. Challenges and implications of using ultrasonic communications in intra-body area networks. In Proceedings of the 2012 9th Annual Conference on Wireless On-Demand Network Systems and Services (WONS), Courmayeur, Italy, 9-11 January 2012; pp. 182-189.

115. Carroll, R.; Cnossen, R.; Schnell, M.; Simons, D. Continua: An interoperable personal healthcare ecosystem. IEEE Pervasive Comput. 2007, 6, 90-94. [CrossRef]

116. Lee, Y.F. An interoperability solution for legacy healthcare devices. IT Prof. 2015, 17, 51-57. [CrossRef]

117. Co, S. Samsung Galaxy Watch Silver 4G. Available online: https://www.samsung.com/us/mobile/wearables/smartwatches/ galaxy-watch--46mm--silver--lte--sm-r805uzsaxar/ (accessed on 17 September 2021).

118. Fraga-Lamas, P.; Fernández-Caramés, T.M.; Suárez-Albela, M.; Castedo, L.; González-López, M. A review on internet of things for defense and public safety. Sensors 2016, 16, 1644. [CrossRef]

119. Hu, X.; Chu, T.H.; Chan, H.C.; Leung, V.C. Vita: A crowdsensing-oriented mobile cyber-physical system. IEEE Trans. Emerg. Top. Comput. 2013, 1, 148-165. [CrossRef]

120. Ismail, L.; Materwala, H.; Zeadally, S. Lightweight blockchain for healthcare. IEEE Access 2019, 7, 149935-149951. [CrossRef]

121. Lin, C.; He, D.; Zeadally, S.; Huang, X.; Liu, Z. Blockchain-based Data Sharing System for Sensing-as-a-Service in Smart Cities. ACM Trans. Internet Technol. (TOIT) 2021, 21, 1-21. [CrossRef]

122. Lu, Y.; Tang, Q.; Wang, G. Zebralancer: Private and anonymous crowdsourcing system atop open blockchain. In Proceedings of the 2018 IEEE 38th International Conference on Distributed Computing Systems (ICDCS), Vienna, Austria, 2-5 July 2018; pp. 853-865.

123. Chatzopoulos, D.; Gujar, S.; Faltings, B.; Hui, P. Privacy preserving and cost optimal mobile crowdsensing using smart contracts on blockchain. In Proceedings of the 2018 IEEE 15th International Conference on Mobile Ad Hoc and Sensor Systems (MASS), Chengdu, China, 9-12 October 2018; pp. 442-450.

124. Huang, J.; Kong, L.; Kong, L.; Liu, Z.; Liu, Z.; Chen, G. Blockchain-based crowd-sensing System. In Proceedings of the 2018 1st IEEE International Conference on Hot Information-Centric Networking (HotICN), Shenzhen, China, 15-17 August 2018; pp. 234-235. 
125. Zhu, S.; Cai, Z.; Hu, H.; Li, Y.; Li, W. zkCrowd: A hybrid blockchain-based crowdsourcing platform. IEEE Trans. Ind. Inform. 2019, 16, 4196-4205. [CrossRef]

126. Kadadha, M.; Otrok, H.; Mizouni, R.; Singh, S.; Ouali, A. SenseChain: A blockchain-based crowdsensing framework for multiple requesters and multiple workers. Future Gener. Comput. Syst. 2020, 105, 650-664. [CrossRef]

127. Kurt Peker, Y.; Rodriguez, X.; Ericsson, J.; Lee, S.J.; Perez, A.J. A cost analysis of internet of things sensor data storage on blockchain via smart contracts. Electronics 2020, 9, 244. [CrossRef]

128. Fu, Y.; Soman, C. Real-time Data Infrastructure at Uber. In Proceedings of the 2021 International Conference on Management of Data, Virtual Event, China, 20-25 June 2021; pp. 2503-2516.

129. Barbeau, S.J.; Perez, R.A.; Labrador, M.A.; Perez, A.J.; Winters, P.L.; Georggi, N.L. A location-aware framework for intelligent real-time mobile applications. IEEE Pervasive Comput. 2010, 10, 58-67. [CrossRef]

130. Barbeau, S.J.; Borning, A.; Watkins, K. OneBusAway multi-region-rapidly expanding mobile transit apps to new cities. J. Public Trans. 2014, 17, 15-34. [CrossRef]

131. Srivastava, M.; Abdelzaher, T.; Szymanski, B. Human-centric sensing. Philos. Trans. R. Soc. Math. Phys. Eng. Sci. 2012, 370, 176-197. [CrossRef] [PubMed]

132. Colomo-Palacios, R.; Gómez-Pulido, J.A.; Pérez, A.J. Intelligent Health Services Based on Biomedical Smart Sensors. Appl. Sci. 2020, 10, 8497. [CrossRef]

133. Burke, J.A.; Estrin, D.; Hansen, M.; Parker, A.; Ramanathan, N.; Reddy, S.; Srivastava, M.B. Participatory sensing. In Proceedings of the Workshop on World-Sensor-Web (WSW'06) at SenSys'06, Boulder, CO, USA, 31 October-3 November 2006; pp. 1-5.

134. Boukhechba, M.; Barnes, L.E. Swear: Sensing using wearables. Generalized human crowdsensing on smartwatches. In Proceedings of the International Conference on Applied Human Factors and Ergonomics, San Diego, CA, USA, 16-20 July 2020; pp. 510-516.

135. Mun, M.; Reddy, S.; Shilton, K.; Yau, N.; Burke, J.; Estrin, D.; Hansen, M.; Howard, E.; West, R.; Boda, P. PEIR, the personal environmental impact report, as a platform for participatory sensing systems research. In Proceedings of the 7 th International Conference on Mobile Systems, Applications, and Services, Krakow, Poland, 22-25 June 2009; pp. 55-68.

136. Yamin M.; Ades Y. Crowd management with RFID and wireless technologies. In Proceedings of the 2009 First International Conference on Networks \& Communications, Chennai, India, 27-29 December 2009; pp. 1-4.

137. Franke, T.; Lukowicz, P.; Blanke, U. Smart crowds in smart cities: Real life, city scale deployments of a smartphone based participatory crowd management platform. J. Internet Serv. Appl. 2015, 6, 1-19. [CrossRef]

138. El Khatib, R.F.; Zorba, N.; Hassanein, H.S. Rapid sensing-based emergency detection: A sequential approach. Comput. Commun. 2020, 159, 222-230. [CrossRef]

139. Rashid, M.T.; Wang, D. CovidSens: A vision on reliable social sensing for COVID-19. Artif. Intell. Rev. 2021, 54, 1-25. [CrossRef]

140. Eisenman, S.B.; Lane, N.D.; Miluzzo, E.; Peterson, R.A.; Ahn, G.S.; Campbell, A.T. Metrosense project: People-centric sensing at scale. In Proceedings of the Workshop on World-Sensor-Web (WSW'06) at SenSys'06, Boulder, CO, USA, 31 October-3 November 2006; pp. 1-5.

141. Balalaie, A.; Heydarnoori, A.; Jamshidi, P. Microservices architecture enables devops: Migration to a cloud-native architecture. IEEE Softw. 2016, 33, 42-52. [CrossRef]

142. Al-Debagy, O.; Martinek, P. A comparative review of microservices and monolithic architectures. In Proceedings of the 2018 IEEE 18th International Symposium on Computational Intelligence and Informatics (CINTI), Budapest, Hungary, 21-22 November 2018; pp. 149-154.

143. Ebert, C.; Gallardo, G.; Hernantes, J.; Serrano, N. DevOps. IEEE Softw. 2016, 33, 94-100. [CrossRef]

144. Perez, A.J.; Zeadally, S.; Cochran, J. A review and an empirical analysis of privacy policy and notices for consumer Internet of things. Secur. Priv. 2018, 1, e15. [CrossRef]

145. Kapadia, A.; Kotz, D.; Triandopoulos, N. Opportunistic sensing: Security challenges for the new paradigm. In Proceedings of the 2009 First International Communication Systems and Networks and Workshops, Bangalore, India, 5-10 January 2009; pp. 1-10.

146. Gilbert, P.; Cox, L.P.; Jung, J.; Wetherall, D. Toward trustworthy mobile sensing. In Proceedings of the Eleventh Workshop on Mobile Computing Systems \& Applications, Annapolis, MD, USA, 22-23 February 2010; pp. 31-36.

147. Rahman, M.; Carbunar, B.; Banik, M. Fit and vulnerable: Attacks and defenses for a health monitoring device. arXiv 2013, arXiv:1304.5672.

148. Shoukry, Y.; Martin, P.; Yona, Y.; Diggavi, S.; Srivastava, M. Pycra: Physical challenge-response authentication for active sensors under spoofing attacks. In Proceedings of the 22nd ACM SIGSAC Conference on Computer and Communications Security, Denver, CO, USA, 12-16 October 2015; pp. 1004-1015.

149. Perez, A.J.; Zeadally, S.; Jabeur, N. Investigating security for ubiquitous sensor networks. Procedia Comput. Sci. 2017, 109, 737-744. [CrossRef]

150. Liu, J.; Sun, W. Smart attacks against intelligent wearables in people-centric internet of things. IEEE Commun. Mag. 2016, 54, 44-49. [CrossRef]

151. Rieck, J. Attacks on fitness trackers revisited: A case-study of unfit firmware security. arXiv 2016, arXiv:1604.03313.

152. Xu, F.; Qin, Z.; Tan, C.C.; Wang, B.; Li, Q. IMDGuard: Securing implantable medical devices with the external wearable guardian. In Proceedings of the 2011 Proceedings IEEE INFOCOM, Shanghai, China, 10-15 April 2011; pp. 1862-1870. 
153. Yan, W.; Hylamia, S.; Voigt, T.; Rohner, C. PHY-IDS: A physical-layer spoofing attack detection system for wearable devices. In Proceedings of the 6th ACM Workshop on Wearable Systems and Applications, Toronto, ON, Canada, 19 June 2020; pp. 1-6.

154. Mendez, D.; Labrador, M.; Ramachandran, K. Data interpolation for participatory sensing systems. Pervasive Mob. Comput. 2013, 9, 132-148. [CrossRef]

155. Mendez, D.; Labrador, M.A. On sensor data verification for participatory sensing systems. J. Netw. 2013, 8, 576. [CrossRef]

156. Bordel, B.; Alcarria, R.; Robles, T.; Sánchez-Picot, Á. Stochastic and information theory techniques to reduce large datasets and detect cyberattacks in Ambient Intelligence Environments. IEEE Access 2018, 6, 34896-34910. [CrossRef]

157. Bordel, B.; Alcarria, R.; Robles, T.; Iglesias, M.S. Data authentication and anonymization in IoT scenarios and future 5G networks using chaotic digital watermarking. IEEE Access 2021, 9, 22378-22398. [CrossRef]

158. Perez, A.J.; Zeadally, S.; Jabeur, N. Security and privacy in ubiquitous sensor networks. J. Inf. Process. Syst. 2018, 14, $286-308$.

159. Chandola, V.; Banerjee, A.; Kumar, V. Anomaly detection: A survey. ACM Comput. Surv. (CSUR) 2009, 41, 1-58. [CrossRef]

160. Trinh, H.D.; Giupponi, L.; Dini, P. Urban anomaly detection by processing mobile traffic traces with LSTM neural networks. In Proceedings of the 2019 16th Annual IEEE International Conference on Sensing, Communication, and Networking (SECON), Boston, MA, USA, 10-13 June 2019; pp. 1-8.

161. Pelati, A.; Meo, M.; Dini, P. A Semi-supervised Method to Identify Urban Anomalies through LTE PDCCH Fingerprinting. In Proceedings of the ICC 2021-IEEE International Conference on Communications, Montreal, QC, Canada, 14-23 June 2021; pp. 1-6.

162. Zhang, M.; Li, T.; Yu, Y.; Li, Y.; Hui, P.; Zheng, Y. Urban anomaly analytics: Description, detection and prediction. IEEE Trans. Big Data 2020. [CrossRef]

163. Vallina-Rodriguez, N.; Crowcroft, J. ErdOS: Achieving energy savings in mobile OS. In Proceedings of the Sixth International Workshop on MobiArch, Bethesda, MD, USA, 28 June 2011; pp. 37-42.

164. Kang, S.; Lee, J.; Jang, H.; Lee, H.; Lee, Y.; Park, S.; Park, T.; Song, J. Seemon: Scalable and energy-efficient context monitoring framework for sensor-rich mobile environments. In Proceedings of the 6th International Conference on Mobile Systems, Applications, and Services, Breckenridge, CO, USA, 17-20 June 2008; pp. 267-280.

165. Dong, M.; Zhong, L. Self-constructive high-rate system energy modeling for battery-powered mobile systems. In Proceedings of the 9th International Conference on Mobile Systems, Applications, and Services, Bethesda, MD, USA, 28 June-1 July 2011 pp. 335-348.

166. Mittal, R.; Kansal, A.; Chandra, R. Empowering developers to estimate app energy consumption. In Proceedings of the 18th Annual International Conference on Mobile Computing and Networking, Istanbul, Turkey, 22-26 August 2012; pp. 317-328.

167. Min, C.; Lee, Y.; Yoo, C.; Kang, S.; Choi, S.; Park, P.; Hwang, I.; Ju, Y.; Choi, S.; Song, J. PowerForecaster: Predicting smartphone power impact of continuous sensing applications at pre-installation time. In Proceedings of the 13th ACM Conference on Embedded Networked Sensor Systems, Seoul, South Korea, 1-4 November 2015; pp. 31-44.

168. Ma, X.; Huang, P.; Jin, X.; Wang, P.; Park, S.; Shen, D.; Zhou, Y.; Saul, L.K.; Voelker, G.M. eDoctor: Automatically Diagnosing Abnormal Battery Drain Issues on Smartphones. In Proceedings of the 10th \{USENIX\} Symposium on Networked Systems Design and Implementation (\{NSDI\} 13), Lombard, IL, USA, 2-5 April 2013; pp. 57-70.

169. Xu, F.; Liu, Y.; Li, Q.; Zhang, Y. V-edge: Fast self-constructive power modeling of smartphones based on battery voltage dynamics. In Proceedings of the 10th USENIX Symposium on Networked Systems Design and Implementation (NSDI 13), Lombard, IL, USA, 2-5 April 2013; pp. 43-55.

170. Pathak, A.; Jindal, A.; Hu, Y.C.; Midkiff, S.P. What is keeping my phone awake? Characterizing and detecting no-sleep energy bugs in smartphone apps. In Proceedings of the 10th International Conference on Mobile Systems, Applications, and Services, Low Wood Bay Lake District, UK, 25-29 June 2012; pp. 267-280.

171. Martin, T.; Hsiao, M.; Ha, D.; Krishnaswami, J. Denial-of-service attacks on battery-powered mobile computers. In Proceedings of the Second IEEE Annual Conference on Pervasive Computing and Communications, Orlando, FL, USA, 14-17 March 2004; pp. 309-318.

172. Newaz, A.K.M.; Sikder, A.K.; Rahman, M.A.; Uluagac, A.S. A survey on security and privacy issues in modern healthcare systems. arXiv 2020, arXiv:2005.07359.

173. Bianchi, A.; Oakley, I. Wearable authentication: Trends and opportunities. Inf. Technol. 2016, 58, 255-262. [CrossRef]

174. Issoufaly, T.; Tournoux, P.U. BLEB: Bluetooth Low Energy Botnet for large scale individual tracking. In Proceedings of the 2017 1st International Conference on Next Generation Computing Applications (NextComp), Reduit, Mauritius, 19-21 September 2017; pp. 115-120.

175. Medina, R.P.; Neundorfer, E.B.; Chouchane, R.; Perez, A. PRAST: Using Logic Bombs to Exploit the Android Permission Model and a Module Based Solution. In Proceedings of the 2018 13th International Conference on Malicious and Unwanted Software (MALWARE), Nantucket, MA, USA, 22-24 October 2018; pp. 1-8.

176. Zhang, Q.; Liang, Z. Security analysis of bluetooth low energy based smart wristbands. In Proceedings of the 2017 2nd International Conference on Frontiers of Sensors Technologies (ICFST), Shenzhen, China, 14-16 April 2017; pp. 421-425.

177. Fereidooni, H.; Classen, J.; Spink, T.; Patras, P.; Miettinen, M.; Sadeghi, A.R.; Hollick, M.; Conti, M. Breaking fitness records without moving: Reverse engineering and spoofing fitbit. In Proceedings of the International Symposium on Research in Attacks, Intrusions, and Defenses, Atlanta, GA, USA, 18-20 September 2017; pp. 48-69.

178. AV-Test. Seven Fitness Wristbands and the Apple Watch in a Security Check. Available online: https://www.av-test.org/en/ news / seven-fitness-wristbands-and-the-apple-watch-in-a-security-check-2016 (accessed on 5 October 2021). 
179. Goyal, R.; Dragoni, N.; Spognardi, A. Mind the tracker you wear: A security analysis of wearable health trackers. In Proceedings of the 31st Annual ACM Symposium on Applied Computing, Pisa, Italy, 4-8 April 2016; pp. 131-136.

180. Sellahewa, H.; Ibrahim, N.; Zeadally, S. Biometric Authentication for Wearables. In Biometric-Based Physical and Cybersecurity Systems; Springer: Berlin/Heidelberg, Germany, 2019; pp. 355-386.

181. Ometov, A.; Petrov, V.; Bezzateev, S.; Andreev, S.; Koucheryavy, Y.; Gerla, M. Challenges of multi-factor authentication for securing advanced IoT applications. IEEE Netw. 2019, 33, 82-88. [CrossRef]

182. Ligatti, J.; Cetin, C.; Engram, S.; Subils, J.B.; Goldgof, D. Coauthentication. In Proceedings of the 34th ACM/SIGAPP Symposium on Applied Computing, Limassol, Cyprus, 8-12 April 2019; pp. 1906-1915.

183. Corn, B.; Perez, A.J.; Ruiz, A.; Cetin, C.; Ligatti, J. An Evaluation of the Power Consumption of Coauthentication as a Continuous User Authentication Method in Mobile Systems. In Proceedings of the 2020 ACM Southeast Conference, Tampa, FL, USA, 2-4 April 2020; pp. 268-271.

184. Robles-Cordero, A.M.; Zayas, W.J.; Peker, Y.K. Extracting the security features implemented in a bluetooth le connection. In Proceedings of the 2018 IEEE International Conference on Big Data (Big Data), Seattle, WA, USA, 10-13 December 2018; pp. 2559-2563.

185. Becker, J.K.; Li, D.; Starobinski, D. Tracking Anonymized Bluetooth Devices. In Proceedings of the 2019 Privacy Enhancing Technologies, Stockholm, Sweden, 16-20 July 2019; pp. 50-65.

186. Knackmuß, J.; Möller, T.; Pommerien, W.; Creutzburg, R. Security risk of medical devices in IT networks-the case of an infusion pump unit. Proc. Spie Int. Soc. Opt. Eng. 2015, 9411. [CrossRef]

187. Krasner, H. The Cost of Poor Software Quality in the US: A 2020 Report. Available online: https://www.it-cisq.org/the-cost-ofpoor-software-quality-in-the-us-a-2020-report.htm (accessed on 5 October 2021).

188. Ramač, R.; Mandić, V.; Taušan, N.; Rios, N.; Freire, S.; Pérez, B.; Castellanos, C.; Correal, D.; Pacheco, A.; Lopez, G.; et al Prevalence, Common Causes and Effects of Technical Debt: Results from a Family of Surveys with the IT Industry. arXiv 2021, arXiv:2109.13771.

189. Kruchten, P.; Nord, R.L.; Ozkaya, I. Technical debt: From metaphor to theory and practice. IEEE Softw. 2012, 29, 18-21. [CrossRef]

190. Applegate, S. The Dawn of Kinetic Cyber. In Proceedings of the 2013 5th International Conference on Cyber Conflict, Tallinn, Estonia, 4-7 June 2013; pp. 1-15.

191. Camara, C.; Peris-Lopez, P.; De Fuentes, J.M.; Marchal, S. Access control for implantable medical devices. IEEE Trans. Emerg. Top. Comput. 2020. [CrossRef]

192. Corbin, B.A. When "Things" Go Wrong: Redefining Liability for the Internet of Medical Things. SCL Rev. $2019,71,1$.

193. Zeadally, S.; Badra, M. Privacy in a Digital, Networked World: Technologies, Implications and Solutions; Springer: Berlin/Heidelberg, Germany, 2015.

194. Motti, V.G.; Caine, K. Users' privacy concerns about wearables. In Proceedings of the International Conference on Financial Cryptography and Data Security, San Juan, PR, USA, 30 January 2015; pp. 231-244.

195. Perez, A.J.; Zeadally, S. PEAR: A privacy-enabled architecture for crowdsensing. In Proceedings of the International Conference on Research in Adaptive and Convergent Systems, Krakow, Poland, 20-23 September 2017; pp. 166-171.

196. Hoh, B.; Gruteser, M.; Herring, R.; Ban, J.; Work, D.; Herrera, J.C.; Bayen, A.M.; Annavaram, M.; Jacobson, Q. Virtual trip lines for distributed privacy-preserving traffic monitoring. In Proceedings of the 6th International Conference on Mobile Systems, Applications, and Services, Breckenridge, CO, USA, 17-20 June 2008; pp. 15-28.

197. Lu, H.; Lane, N.; Eisenman, S.; Campbell, A. Bubble-sensing: A new paradigm for binding a sensing task to the physical world using mobile phones. In Proceedings of the Workshop on Mobile Devices and Urban Sensing, St. Louis, MO, USA, 22-24 April 2008; pp. 1-8.

198. Christin, D.; López, P.S.; Reinhardt, A.; Hollick, M.; Kauer, M. Share with strangers: Privacy bubbles as user-centered privacy control for mobile content sharing applications. Inf. Secur. Tech. Rep. 2013, 17, 105-116. [CrossRef]

199. Kapadia, A.; Henderson, T.; Fielding, J.J.; Kotz, D. Virtual walls: Protecting digital privacy in pervasive environments. In Proceedings of the International Conference on Pervasive Computing, White Plains, NY, USA, 19-23 March 2007; pp. 162-179.

200. Truong, K.N.; Patel, S.N.; Summet, J.W.; Abowd, G.D. Preventing camera recording by designing a capture-resistant environment. In Proceedings of the International Conference on Ubiquitous Computing, Tokyo, Japan, 11-14 September 2005; pp. 73-86.

201. Tiscareno, V.; Johnson, K.; Lawrence, C. Systems and Methods for Receiving Infrared Data with a Camera Designed to Detect Images Based on Visible Light. US Patent 8,848,059, 30 September 2014.

202. Wagstaff, J. Using Bluetooth to Disable Camera Phones. Available online: http://www.loosewireblog.com/2004/09/using bluetooth.html (accessed on 17 September 2021).

203. Blank, P.; Kirrane, S.; Spiekermann, S. Privacy-aware restricted areas for unmanned aerial systems. IEEE Secur. Priv. 2018, 16, 70-79. [CrossRef]

204. Steil, J.; Koelle, M.; Heuten, W.; Boll, S.; Bulling, A. Privaceye: Privacy-preserving head-mounted eye tracking using egocentric scene image and eye movement features. In Proceedings of the 11th ACM Symposium on Eye Tracking Research \& Applications, Denver, CO, USA, 25-28 June 2019; pp. 1-10.

205. Yamada, T.; Gohshi, S.; Echizen, I. Use of invisible noise signals to prevent privacy invasion through face recognition from camera images. In Proceedings of the 20th ACM International Conference on MULTIMEDIA, Nara, Japan, 29 October-2 November 2012; pp. 1315-1316. 
206. Yamada, T.; Gohshi, S.; Echizen, I. Privacy visor: Method based on light absorbing and reflecting properties for preventing face image detection. In Proceedings of the 2013 IEEE International Conference on Systems, Man, and Cybernetics, Manchester, UK, 13-16 October 2013; pp. 1572-1577.

207. Sharif, M.; Bhagavatula, S.; Bauer, L.; Reiter, M.K. Accessorize to a crime: Real and stealthy attacks on state-of-the-art face recognition. In Proceedings of the 2016 ACM Sigsac Conference on Computer and Communications Security, Vienna, Austria, 24-28 October 2016; pp. 1528-1540.

208. Schiff, J.; Meingast, M.; Mulligan, D.K.; Sastry, S.; Goldberg, K. Respectful cameras: Detecting visual markers in real-time to address privacy concerns. In Protecting Privacy in Video Surveillance; Springer: Berlin/Heidelberg, Germany, 2009 ; pp. 65-89.

209. Ye, T.; Moynagh, B.; Albatal, R.; Gurrin, C. Negative faceblurring: A privacy-by-design approach to visual lifelogging with google glass. In Proceedings of the 23rd ACM International Conference on Conference on Information and Knowledge Management, Shanghai, China, 3-7 November 2014; pp. 2036-2038.

210. Perez, A.J.; Zeadally, S.; Matos Garcia, L.Y.; Mouloud, J.A.; Griffith, S. FacePET: Enhancing bystanders' facial privacy with smart wearables/internet of things. Electronics 2018, 7, 379. [CrossRef]

211. Aditya, P.; Sen, R.; Druschel, P.; Joon Oh, S.; Benenson, R.; Fritz, M.; Schiele, B.; Bhattacharjee, B.; Wu, T.T. I-pic: A platform for privacy-compliant image capture. In Proceedings of the 14th Annual International Conference on Mobile Systems, Applications, and Services, Singapore, 26-30 June 2016; pp. 235-248.

212. Samarati, P. Protecting respondents identities in microdata release. IEEE Trans. Knowl. Data Eng. 2001, 13, 1010-1027. [CrossRef]

213. Machanavajjhala, A.; Kifer, D.; Gehrke, J.; Venkitasubramaniam, M. 1-diversity: Privacy beyond k-anonymity. ACM Trans. Knowl. Discov. Data (TKDD) 2007, 1, 3-es. [CrossRef]

214. Li, N.; Li, T.; Venkatasubramanian, S. t-closeness: Privacy beyond k-anonymity and l-diversity. In Proceedings of the 2007 IEEE 23rd International Conference on Data Engineering, Istanbul, Turkey, 11-15 April 2007; pp. 106-115.

215. Dwork, C. Differential privacy: A survey of results. In Proceedings of the International Conference on Theory and Applications of Models of Computation, Xi'an, China, 25-29 May 2008; pp. 1-19.

216. Dwork, C.; Roth, A. The algorithmic foundations of differential privacy. Found. Trends Theor. Comput. Sci. 2014, 9, $211-407$. [CrossRef]

217. Gentry, C. Fully homomorphic encryption using ideal lattices. In Proceedings of the 41st Annual ACM Symposium on Theory of Computing, Bethesda, MD, USA, 31 May-2 June 2009; pp. 169-178.

218. Acar, A.; Aksu, H.; Uluagac, A.S.; Conti, M. A survey on homomorphic encryption schemes: Theory and implementation. ACM Comput. Surv. (CSUR) 2018, 51, 1-35. [CrossRef]

219. Palen, L.; Salzman, M.; Youngs, E. Going wireless: Behavior \& practice of new mobile phone users. In Proceedings of the 2000 ACM Conference on Computer Supported Cooperative Work, Philadelphia, PA, USA, 2-6 December 2000; pp. 201-210.

220. Denning, T.; Dehlawi, Z.; Kohno, T. In situ with bystanders of augmented reality glasses: Perspectives on recording and privacy-mediating technologies. In Proceedings of the 2014 SIGCHI Conference on Human Factors in Computing Systems, Toronto, ON, Canada, 26 April-1 May 2014; pp. 2377-2386.

221. Hoyle, R.; Templeman, R.; Armes, S.; Anthony, D.; Crandall, D.; Kapadia, A. Privacy behaviors of lifeloggers using wearable cameras. In Proceedings of the 2014 ACM International Joint Conference on Pervasive and Ubiquitous Computing, Seattle, WA, USA, 13-17 September 2014; pp. 571-582.

222. Zhang, S.; Feng, Y.; Das, A.; Bauer, L.; Cranor, L.F.; Sadeh, N. Understanding people's privacy attitudes towards video analytics technologies. In Proceedings of the FTC PrivacyCon 2020, Washington, DC, USA, 21 July 2020; pp. 1-18.

223. Hoyle, R.; Stark, L.; Ismail, Q.; Crandall, D.; Kapadia, A.; Anthony, D. Privacy norms and preferences for photos posted online. ACM Trans. Comput. Hum. Interact. (TOCHI) 2020, 27, 1-27. [CrossRef]

224. Ahmad, I.; Farzan, R.; Kapadia, A.; Lee, A.J. Tangible privacy: Towards user-centric sensor designs for bystander privacy. Proc. ACM Hum. Comput. Interact. 2020, 4, 1-28. [CrossRef]

225. Wang, Y.; Xia, H.; Yao, Y.; Huang, Y. Flying Eyes and Hidden Controllers: A Qualitative Study of People's Privacy Perceptions of Civilian Drones in The US. Proc. Priv. Enhancing Technol. 2016, 2016, 172-190. [CrossRef]

226. Chang, V.; Chundury, P.; Chetty, M. Spiders in the sky: User perceptions of drones, privacy, and security. In Proceedings of the 2017 CHI Conference on Human Factors in Computing Systems, Denver, CO, USA, 6-11 May 2017; pp. 6765-6776.

227. Perez, A.J.; Zeadally, S.; Griffith, S.; Garcia, L.Y.M.; Mouloud, J.A. A User Study of a Wearable System to Enhance Bystanders' Facial Privacy. IoT 2020, 1, 198-217. [CrossRef]

228. Hatuka, T.; Toch, E. Being visible in public space: The normalisation of asymmetrical visibility. Urban Stud. 2017, 54, 984-998. [CrossRef]

229. De Capitani Di Vimercati, S.; Foresti, S.; Livraga, G.; Samarati, P. Data privacy: Definitions and techniques. Int. J. Uncertain. Fuzziness Knowl. Based Syst. 2012, 20, 793-817. [CrossRef]

230. Abadi, M.; Chu, A.; Goodfellow, I.; McMahan, H.B.; Mironov, I.; Talwar, K.; Zhang, L. Deep learning with differential privacy. In Proceedings of the 2016 ACM SIGSAC Conference on Computer and Communications Security, Vienna, Austria, 24-28 October 2016; pp. 308-318.

231. Hassija, V.; Chamola, V.; Bajpai, B.C.; Zeadally, S. Security issues in implantable medical devices: Fact or fiction? Sustain. Cities Soc. 2020, 102552. [CrossRef] 
232. Xu, T.; Wendt, J.B.; Potkonjak, M. Security of IoT systems: Design challenges and opportunities. In Proceedings of the 2014 IEEE/ACM International Conference on Computer-Aided Design (ICCAD), San Jose, CA, USA, 3-6 November 2014; pp. 417-423.

233. Sequeiros, J.B.; Chimuco, F.T.; Samaila, M.G.; Freire, M.M.; Inácio, P.R. Attack and system modeling applied to IoT, cloud, and mobile ecosystems: Embedding security by design. ACM Comput. Surv. (CSUR) 2020, 53, 1-32. [CrossRef]

234. Antonakakis, M.; April, T.; Bailey, M.; Bernhard, M.; Bursztein, E.; Cochran, J.; Durumeric, Z.; Halderman, J.A.; Invernizzi, L.; Kallitsis, M.; et al. Understanding the mirai botnet. In Proceedings of the 26th USENIX Security Symposium (USENIX SECURITY 17), Vancouver, BC, Canada, 16-18 August 2017; pp. 1093-1110.

235. Sadeh, N.; Acquisti, A.; Breaux, T.D.; Cranor, L.F.; McDonald, A.M.; Reidenberg, J.R.; Smith, N.A.; Liu, F.; Russell, N.C.; Schaub, F.; et al. The Usable Privacy Policy Project. 2013. Available online: http://ra.adm.cs.cmu.edu/anon/usr0/ftp/home/anon/isr2 013/CMU-ISR-13-119.pdf (accessed on 5 October 2021).

236. Goddard, M. The EU General Data Protection Regulation (GDPR): European regulation that has a global impact. Int. J. Mark. Res. 2017, 59, 703-705. [CrossRef]

237. Giordani, M.; Polese, M.; Mezzavilla, M.; Rangan, S.; Zorzi, M. Toward 6G networks: Use cases and technologies. IEEE Commun. Mag. 2020, 58, 55-61. [CrossRef]

238. Zhang, Z.; Xiao, Y.; Ma, Z.; Xiao, M.; Ding, Z.; Lei, X.; Karagiannidis, G.K.; Fan, P. 6G wireless networks: Vision, requirements, architecture, and key technologies. IEEE Veh. Technol. Mag. 2019, 14, 28-41. [CrossRef]

239. Li, T.; Sahu, A.K.; Talwalkar, A.; Smith, V. Federated learning: Challenges, methods, and future directions. IEEE Signal Process. Mag. 2020, 37, 50-60.

240. Niknam, S.; Dhillon, H.S.; Reed, J.H. Federated learning for wireless communications: Motivation, opportunities, and challenges. IEEE Commun. Mag. 2020, 58, 46-51. [CrossRef]

241. Rieke, N.; Hancox, J.; Li, W.; Milletari, F.; Roth, H.R.; Albarqouni, S.; Bakas, S.; Galtier, M.N.; Landman, B.A.; Maier-Hein, K.; et al. The future of digital health with federated learning. NPJ Digit. Med. 2020, 3, 1-7. [CrossRef]

242. Huynh, L.N.; Lee, Y.; Balan, R.K. Deepmon: Mobile gpu-based deep learning framework for continuous vision applications. In Proceedings of the 15th Annual International Conference on Mobile Systems, Applications, and Services, Niagara Falls, NY, USA 19-23 June 2017; pp. 82-95.

243. Wang, Y.; Wang, J.; Zhang, W.; Zhan, Y.; Guo, S.; Zheng, Q.; Wang, X. A survey on deploying mobile deep learning applications: A systemic and technical perspective. Digit. Commun. Netw. 2021. [CrossRef]

244. Joshi, V.; Le Gallo, M.; Haefeli, S.; Boybat, I.; Nandakumar, S.R.; Piveteau, C.; Dazzi, M.; Rajendran, B.; Sebastian, A.; Eleftheriou, E. Accurate deep neural network inference using computational phase-change memory. Nat. Commun. 2020, 11, 1-13. [CrossRef]

245. Smil, V. Embodied energy: Mobile devices and cars [Numbers Don't Lie]. IEEE Spectr. 2016, 53, 26. [CrossRef]

246. Leontief, W. Input-Output Economics; Oxford University Press: Oxford, UK, 1986.

247. Humar, I.; Ge, X.; Xiang, L.; Jo, M.; Chen, M.; Zhang, J. Rethinking energy efficiency models of cellular networks with embodied energy. IEEE Netw. 2011, 25, 40-49. [CrossRef]

248. Bello, G.; Perez, A.J. On the Application of Financial Security Standards in Blockchain Platforms. In Blockchain Cybersecurity, Trust and Privacy; Choo, K.K.R., Dehghantanha, A., Parizi, R.M., Eds.; Springer: Cham, Switzerland, 2020; pp. 247-267. [CrossRef]

249. PCI. Payment Application Data Security Standard. Available online: https://www.pcisecuritystandards.org/minisite/en/padss-v2-0.php (accessed on 1 October 2021).

250. Landi, H. Google Closes \$2.1B Acquisition of Fitbit as Justice Department Probe Continues. Available online: https:// www.fiercehealthcare.com/tech/google-closes-2-1b-acquisition-fitbit-as-justice-department-probe-continues (accessed on 1 October 2021).

251. Virgin Pulse Support. Available online: https://virginpulse.zendesk.com/hc/en-us/categories/200339624-DEVICES-APPS (accessed on 1 October 2021).

252. Appenzeller, A. Privacy and Patient Involvement in e-Health Worldwide: An International Analysis. In Proceedings of the 2020 Workshop of Fraunhofer IOSB and Institute for Anthropomatics, Vision and Fusion Laboratory, Karlsruhe, Germany, 27-31 July 2020; pp. 1-17.

253. Häyrinen, K.; Saranto, K.; Nykänen, P. Definition, structure, content, use and impacts of electronic health records: A review of the research literature. Int. J. Med Inform. 2008, 77, 291-304. [CrossRef]

254. U.S. Food and \& Drug Administration: Medical Devices. Available online: https:/ /www.fda.gov/medical-devices (accessed on 1 October 2021).

255. FDA. Content of Premarket Submissions for Management of Cybersecurity in Medical Devices. Available online: https: / / www.fda.gov / regulatory-information/search-fda-guidance-documents / content-premarket-submissions-managementcybersecurity-medical-devices-0 (accessed on 28 September 2021).

256. Jennings, K. The Billionaire Who Controls Your Medical Records. Available online: https://www.forbes.com/sites/katiejennings/ 2021/04/08/billionaire-judy-faulkner-epic-systems / (accessed on 1 October 2021).

257. Commonwell Health Alliance. Available online: https://www.commonwellalliance.org/ (accessed on 1 October 2021).

258. H.R. 748-CARES Act. Available online: https://www.congress.gov/bill/116th-congress/house-bill/748/ (accessed on 1 October 2021).

259. United States Core Data for Interoperability (USCDI). Available online: https://www.healthit.gov/isa/united-states-core-datainteroperability-uscdi (accessed on 1 October 2021). 